Research Article

\title{
Optimal Showroom Service Strategy and Power Structure for Retailers considering Consumer Return
}

\author{
Xuemei Zhang $\left(\mathbb{D},{ }^{1,2}\right.$ Haoran Chen, ${ }^{1}$ Jiawei Hu, ${ }^{1}$ Chenhao Ma, ${ }^{1}$ and Wei Shi $\mathbb{D}^{1,2}$ \\ ${ }^{1}$ Business School, Fuyang Normal University, Fuyang, Anhui, 236037, China \\ ${ }^{2}$ Anhui Provincial Key Laboratory of Regional Logistics Planning and Modern Logistics Engineering, Fuyang Normal University, \\ Fuyang, Anhui, 236037, China \\ Correspondence should be addressed to Wei Shi; lishuer@fynu.edu.cn
}

Received 29 April 2021; Revised 18 June 2021; Accepted 16 July 2021; Published 30 July 2021

Academic Editor: Ya Jia

Copyright (c) 2021 Xuemei Zhang et al. This is an open access article distributed under the Creative Commons Attribution License, which permits unrestricted use, distribution, and reproduction in any medium, provided the original work is properly cited.

\begin{abstract}
This paper investigates the optimal showroom service strategy and power structure for online and offline retailers considering online consumer return. Combining two service strategies and three competition power structures, six models are constructed to analyze the effects of the showrooming effect and consumer return on retailers' decisions and consumer surplus. The results show that the SS strategy is the best choice for offline retailers, and it is also an effective way to solve consumer return. Online retailers are suggested to cooperate with offline retailers to implement SS strategy and enhance the showrooming effect. Under the SS strategy, the offline-led power structure is the best choice for online retailers, but the online-led power structure is optimal for offline retailers. We also find that the supply chain and consumers are more likely to implement SS strategy and offline-led power structure. More importantly, we pinpoint that there is no incentive for retailers to implement the Nash power structure. Therefore, it is recommended to revitalize the real economy of offline retailers and implement the strategy SS effectively.
\end{abstract}

\section{Introduction}

With the application of e-commerce and Internet, online shopping has been widely recognized by consumers [1]. Online retailers such as Tmall.com and JD.com have gained a larger market share and interests, and the competition with offline retailers is becoming more and more fierce [2]. For example, in the recent Tmall "Double Eleven" shopping festival in 2020, the turnover was as high as $\$ 76.94$ billion in just one day [2]. Facing competitive pressure from online retailers, traditional offline retailers provide offline showroom service to encourage more potential consumers to take advantages of offline channels $[3,4]$. However, the offline showroom service provided by offline retailers has a "showrooming" effect on demand for online channels for online retailers [4-6]. Offline retailers need to weigh the input costs and benefits to decide whether to provide offline showroom service [7]. Therefore, when online and offline retailers make competitive decisions, they need to consider the influence of the showrooming effect and adopt an appropriate showroom service strategy [8].
Online shopping brings convenience to consumers and benefits to online retailers, but the biggest disadvantage of online shopping channel is the inability to accurately evaluate the suitability of products before purchasing [9]. After online shopping, consumers typically check the "fit" at home, and as a result, a third of all Internet sales get returned $[10,11]$. Particularly in the retail industry, the return rate of consumers is higher [12]. For example, Wal-Mart provides full credit for consumer returns under very broad circumstances [13]. Most consumer returns are due to misfit, as determined by the consumer after purchase [14-16]. Many enterprises are adopting consumer return guarantee strategy, advertising, and offline showroom service to reduce consumer returns [17]. However, consumer returns policies also increase cost and bring negative impacts on retailers' benefits [13]. Therefore, it has become a critical issue to understand the effect of consumer return behavior for online and offline retailers [18].

Although online shopping is becoming more and more popular, offline retail stores also play an irreplaceable role. Consumers can easily view demonstrated products through 
an offline channel to perception of product quality $[19,20]$. In various industries, online and offline retailers have unequal levels of channel power [21]. In some industries, traditional retail still dominates the market due to its unique advantages, for example, automobile industry, service industry, and catering industry [22]. Therefore, different power structures may affect the decision sequences of the players and in turn supply chain operation performance $[21,23,24]$. In the marketing industry, the online retailers, such as Amazon, are usually the leader [25]. But some large retailers, such as Walmart, are the leader [21]. From a supply chain performance perspective, the supply chain members should determine optimal showroom service strategy and power structure to improve supply chain performance considering consumer return.

The aforementioned examples emphasize the importance of power structure, showrooming effect, and consumer return for online and offline retailers. However, there has been a lack of analytical research examining this issue. In this paper, we attempt to examine the optimal showroom service strategy and power structure by incorporating consumer return. Particularly, this research will address the following questions:

(1) What is the optimal showroom service strategy? What is the impact of the showrooming effect on profits of retailers, supply chain performance, and consumers?

(2) What is the effect of consumer return on the decisions of online and offline retailers and consumer surplus?

(3) Whether the online/offline dominant power structure is beneficial to the online/offline retailers, the supply chain operation, and consumers?

To investigate the above research questions, we develop a game analytical model that an offline retailer provides offline showroom service and an online retailer designs strategy to deal with consumer return. To examine the effect of power structure, we consider an offline-lead game, an online-lead game, and a Nash game. Therefore, six models are constructed: (1) offline-led game with NSS/SS (No Showroom Service/Showroom Service) strategy $(N R / R)$, (2) online-led game with NSS/SS strategy $(N D / D)$, and (3) Nash game with NSS/SS strategy $(N N / N)$.

The remainder of this paper is organized as follows. Section 2 reviews the existing related literature. In Section 3, the problem and model assumptions are described. Section 4 presents the Stackelberg and Nash equilibrium results of the six models of retailers. Section 5 performs a comparison analysis for the research results of six models. Section 6 gives the numerical analysis. The conclusions are summarized in Section 7.

\section{Literature Review}

There are three main streams of literature closed related to this study, namely, showrooming effect in supply chain, consumer return in operations management, and channel power structures. To highlight the main contributions of this paper, we review related works of each stream in the following.

2.1. Showrooming Effect in Supply Chain. The first stream of literature concerns the showrooming effect, which has received considerable attention in supply chain management [3, 4, 8, 26-29]. The majority of previous researches focus on the negative impact of showrooming on the decisions and performance of the supply chain and put forward a solution strategy [3, 4, 30]. Specifically, Li et al. [3] show that the firms can obtain higher profit using the ex-post service strategy when the showrooming effect is greater. Liu et al. [31] find that a well-designed dual-channel system can indeed improve the retailer's profitability considering the showrooming effect. While price-matching could be used, Mehra et al. [32] analyze the influence of showrooming on consumers' purchase behavior. Rapp et al. [33] analyze the showrooming effect on adjusting the sales staff's crossselling strategy through empirical analysis. Basu et al. [34] analyze the influence of the showrooming effect on retailers' profit and find the disadvantage of the showrooming effect. Schneider and Zielke [35] investigate how offline retailers can compensate for a price disadvantage against the online channel with service strategies and find that price fairness mediates these effects. All of the above studies investigate the decisions problem considering the negative effect of showrooming. But the showrooming also has a positive effect; for example, Goraya et al. [36] find that showrooming and webrooming moderated the positive impact of channel integration on online/offline patronage intentions. Different from the above studies, this paper introduces the showroom service strategy to mitigate consumer return and examine how the consumer return affects the optimal showroom service strategy and power structure.

2.2. Consumer Return in Operations Management. There are many papers examining the consumer return in operations management $[9,12,13,37-39]$. Many existing studies have focused on the effect of consumer return on decisions (e.g., pricing strategy) and performance of the supply chain $[13,40]$. In particular, Yang et al. [12] show that a moneyback guarantee enhances the profits of the manufacturer with a low satisfaction rate; it also enhances the retailer's profit and expands the overall market. Ren et al. [13] propose dual-channel supply chain models involving consumer returns. Radhi and Zhang [41] investigate the optimal pricing strategies of dual-channel retailers and discuss the effect of consumer preference and consumer return on the pricing strategy. Some studies also investigate the countermeasures for consumer return behavior. For instance, Akturk et al. [42] examine retail abuse with respect to both opportunistic and fraudulent consumer behavior and evaluate two innovative technology-enabled countermeasures to mitigate return abuse. Ren et al. [43] investigate the optimal pricing strategy and return and return insurance strategy and give the conditions of providing different strategies. Javadi et al. [44] find that, under the price 
incentive mechanism, the implementation of full refund can improve the performance of supply chain and government. However, few papers have investigated the effect of consumer return on the optimal power structure, and the existing papers also rarely consider the showroom service strategy and power structure at the same time. Accordingly, this paper attempts to examine which showroom service strategy and power structure are optimal for retailers considering consumer return and showrooming effect.

2.3. Channel Power Structures. In the last research stream, a number of studies focus on channel power structures in supply chain system [45-47]. Li et al. [19] investigate the effect of different power structures on the efficacy of manufacturer advertising, retailer advertising, and cooperative advertising in a dual-exclusive channel system. Zhang et al. [23] find that if the manufacturer adopts a green technology strategy, the power structure will not affect social welfare. If the manufacturer purchases carbon credits, the government under the power structure of Vertical Nash will gain the most social welfare. Zheng et al. [24] find that the manufacturer prefers the power structure of manufacturer-Stackelberg, Nash, and retailer-Stackelberg in turn as the degree of channel competition increases. Taking two competitive recycling channels, retailer recycling and third-party recycling, as examples, Ranjbar et al. [25] evaluate the optimal pricing and recycling decisionmaking and find that the retailer leadership model is optimal. Luo et al. [48] find that power structures have no influence on the decision-making of retailers but have an influence on the pricing strategy and performance of supply chain members. Agi and Yan [49] find that a manufacturer-led supply chain system is better to overcome the fixed cost. In reality, online retailers have more and more power; this motivates us to pay attention to the power structure. These studies only explore the channel power structure issue in supply chain. But they do not consider the influences of consumer return. Our paper differs considering both the showrooming effect and consumer return and puts forward optimal showroom service strategy and power structure.

To summarize, this is the first paper to investigate the combined effect of the showrooming effect and consumer return on the channel power structure, supply chain performance, and consumer surplus. From the perspective of retailers, our findings help retailers to make a decision on showroom service strategy and select optimal power structure according to the showrooming effect and consumer return behavior. Thus, the main contributions of this paper are as follows: (1) Exploring which power structure is more beneficial to supply chain operation: the decisions of online and offline retailers are investigated under different models. (2) Structuring six models to analyze the impact of the showrooming effect on the decisions of online and offline retailers and power structure: the optimal power structure and showroom service strategy are proposed. (3) Investigating the effect of consumer return behavior on retailers' profits and consumer surplus.

\section{Problem Description and Model Assumptions}

We consider an offline retailer and an online retailer to sell homogeneous products to consumers through offline and online channels, respectively. Since online experience is not available, online consumers have a certain probability of return behavior. Considering the consumer return behavior, the offline retailer decides whether to provide offline showroom service. One is called NSS (No Showroom Service) strategy, and the other is called SS (Showroom Service) strategy. In a decentralized dual-channel scenario considering the showrooming effect and consumer return, threechannel power structures will be examined: offline-led game, online-led game, and Nash game [50]. The two retailers play offline or online Stackelberg dynamic or Nash static games. Considering whether to provide offline showroom service and different channel power structures, six models are found: offline-led game with NSS/SS strategy (model NR/R), online-led game with NSS/SS strategy (model $N D / D$ ), and Nash game with NSS/SS strategy (model NN/N). The channel structure with consumer return and showrooming effect is shown in Figure 1.

The symbols and notations used throughout this paper are given in Table 1.

To make the analysis tractable, we introduce the following assumptions in this research.

Assumption 1. The market demand for each channel is a linear function of price and offline showroom service level [6]. The demand functions for the online and offline channels are $D_{d}=\alpha Q-p_{d}+\beta p_{r}+\rho e$ and $D_{r}=(1-\alpha) Q-$ $p_{r}+\beta p_{d}+e$, respectively $[6,51]$, where $0<\alpha<1$ and $0<\beta<1$. Without loss of generality, following Zhang et al. [52], Zhang et al. [53], Li et al. [6], and Li et al. [7], we set $Q=1$.

Assumption 2. The positive cross effect between the increased demand for offline and online channels is considered [6]. Moreover, in order to ensure that the profits of the two channels are positive and generate interesting managerial insights, $0<\rho<\left(\left(2 \sqrt{2-\beta^{2}}-2\right) / \beta\right)$ is assumed $[6,54]$.

Assumption 3. Consumers who buy products through the online channel may choose to return products $[55,56]$; the return rate is assumed to be less than one; that is, $0<r<1$ $[37,57]$. Consumers receive a full refund for returned products [41].

Assumption 4. The offline showroom service cost is a convex function of service level, which is formulated as $C(e)=e^{2} / 2$, which satisfies that $C(0)=0, \partial C(e) / \partial e>0$, and $\partial^{2} C(e) /$ $\partial e^{2}>0[6,52,58]$.

Assumption 5. In order to prevent the retailers from gaining more profits for the salvage value of the returned products than selling products, $0<s<c+c_{h}<1$ is assumed [17, 41]. Let $\phi=c_{h}-s$ denote marginal additional cost for returned 


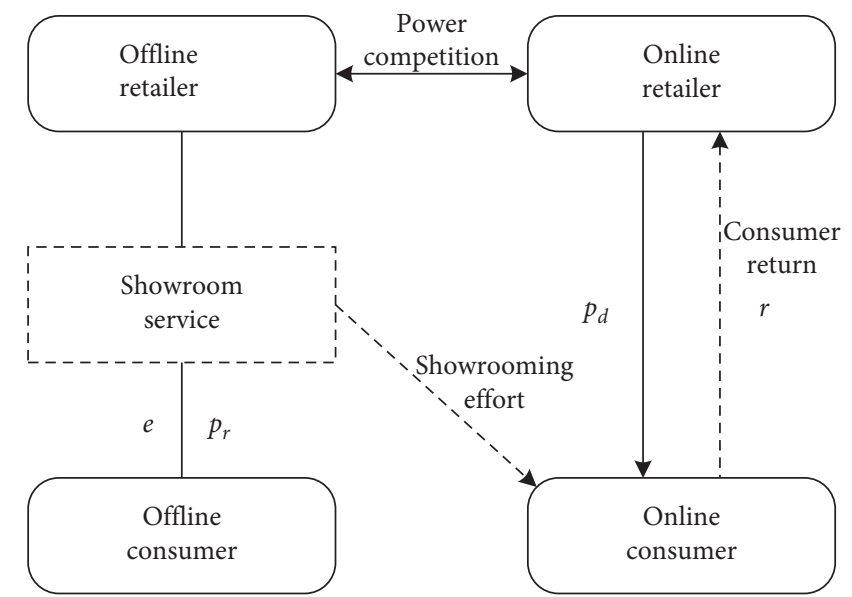

FIGURE 1: Channel structure with consumer return and showrooming effect.

TABLE 1: Symbols and notations.

\begin{tabular}{lc}
\hline Symbol & Definition \\
\hline$c$ & Unit purchasing cost \\
$c_{h}$ & $\begin{array}{c}\text { Unit handling cost of returned products } \\
s \\
r\end{array}$ \\
$\alpha$ & $\begin{array}{c}\text { Cnit salvage value of returned products } \\
\text { Consumer return rate }\end{array}$ \\
$\beta$ & Demand proportion of online channel \\
$\rho$ & Total market demand \\
$e$ & Cross price elasticity coefficient between two channels \\
$p_{d} / p_{r}$ & Showrooming effect coefficient \\
$C(e)$ & Offline showroom service level \\
$D_{j}^{i}$ & Unit retail price of products sold through online/offline channel \\
$\Pi_{j}^{l}$ & Offline showroom service cost \\
\hline
\end{tabular}

products; then we have $0<\phi<1$. In addition, to ensure that the demands are positive, we assume $0<c<((2-2 \alpha+$ $\left.\alpha \beta) /\left(2-2 \beta^{2}\right)\right)$.

In the following, the superscript $i$ represents each model, where $i \in\{N R, N D, N N, R, D, N\}$. In the models $R, D$, and $N$, the offline retailer decides the retail price of the offline channel and the showroom service level at the same time.

\section{Model Formulations and Equilibrium Analysis}

To investigate the impact of consumer return on showroom service strategy, power structure, and supply chain performance, we first explore the offline-led game (model $(N R / R)$ ) in Section 4.1 and then the online-led game (model $(N D / D)$ ) in Section 4.2. Finally, the Nash game (model $(N N / N))$ is analyzed in Section 4.3.

4.1. Offline-Led Game. In the offline-led game, the offline retailer is the leader and the online retailer is the follower. To investigate the optimal showroom service strategy, we first establish a benchmark scenario with the NSS strategy. Next, the model with the SS strategy is explored.
4.1.1. Model NR (Strategy NSS). In the model NR, the offline retailer adopts strategy NSS, which means that he does not offer offline showroom service; that is, $e=0$. The offline retailer firstly decides the retail price of the offline channel $p_{r}^{N R}$, and then the online retailer decides the retail price of the online channel $p_{d}^{N R}$. The optimal model is formulated as

$$
\begin{aligned}
& \max _{p_{r}^{N R}} \Pi_{r}^{N R}=\left(p_{r}^{N R}-c\right)\left(1-\alpha-p_{r}^{N R}+\beta p_{d}^{N R}\right) \\
\text { s.t. } \quad & \max _{p_{d}^{N R}} \Pi_{d}^{N R}=\left[(1-r) p_{d}^{N R}-c-r \phi\right]\left(\alpha-p_{d}^{N R}+\beta p_{r}^{N R}\right) .
\end{aligned}
$$

By using the reverse induction method, we have the optimal results for the model $N R$, which are shown in Proposition 1.

Proposition 1. In the model $N R$, the optimal prices are given as $p_{d}^{N R^{*}}=\left(\left(\left(4-\beta^{2}\right)(c+r \phi)\right) /\left(4(1-r)\left(2-\beta^{2}\right)\right)\right)+$ $\left(\left(\left(4-\beta^{2}\right) \alpha+2 \beta(1-\alpha)\right) /\left(4\left(2-\beta^{2}\right)\right)\right)+(\beta c / 4)$ and $p_{r}^{N R^{*}}=$ $\left((\beta \quad(c+r \phi)) / 2(1-r)\left(2-\beta^{2}\right)\right)+((\alpha \beta+2(1-\alpha)) /(2(2-$ $\left.\left.\beta^{2}\right)\right)+(c / 2)$. 
Proof. The proof is given in Appendix A.

$$
\begin{aligned}
& D_{d}^{N R^{*}}=\frac{\left(4-\beta^{2}\right) \alpha+2 \beta(1-\alpha)}{4\left(2-\beta^{2}\right)}+\frac{\beta c}{4}+\frac{\left(3 \beta^{2}-4\right)(c+r \phi)}{4(1-r)\left(2-\beta^{2}\right)}, \\
& D_{r}^{N R^{*}}=\frac{\beta(c+r \phi)}{4(1-r)}+\frac{2(1-\alpha)+c\left(\beta^{2}-2\right)+\alpha \beta}{4}, \\
& \Pi_{d}^{N R^{*}}=\frac{\left[\left(4 \alpha+2 \beta c-\beta^{3} c+2 \beta-2 \alpha \beta-\alpha \beta^{2}\right)(1-r)+\left(3 \beta^{2}-4\right)(c+r \phi)\right]^{2}}{16\left(2-\beta^{2}\right)^{2}(1-r)}, \\
& \Pi_{r}^{N R^{*}}=\frac{\left[\left(2-2 \alpha-2 c+\beta^{2} c+\alpha \beta\right)(1-r)+\beta(c+r \phi)\right]^{2}}{8\left(2-\beta^{2}\right)^{2}(1-r)}, \\
& \Pi_{s}^{N R^{*}}=\Pi_{d}^{N R^{*}}+\Pi_{r}^{N R^{*}} \cdot
\end{aligned}
$$

4.1.2. Model $R$ (Strategy SS). In the model $R$, the offline retailer implements strategy SS; that is to say, he offers offline showroom service, that is, $e^{R}>0$. The offline retailer firstly decides the retail price of the offline channel $p_{r}^{R}$ and showroom service $e^{R}$, and then the online retailer decides the retail price of the online channel $p_{d}^{R}$. The optimal model is formulated as

$$
\begin{aligned}
& \max _{p_{r}^{R}, e^{R}} \Pi_{r}^{R}=\left(p_{r}^{R}-c\right)\left(1-\alpha-p_{r}^{R}+\beta p_{d}^{R}+e^{R}\right)-\frac{1}{2} e^{R 2} \\
\text { s.t. } & \max _{p_{d}^{R}} \Pi_{d}^{R}=\left[(1-r) p_{d}^{R}-c-r \phi\right]\left(\alpha-p_{d}^{R}+\beta p_{r}^{R}+\rho e^{R}\right) .
\end{aligned}
$$

The optimal results in the model $R$ can be obtained by using the reverse induction method, which are shown in Proposition 2.

Proposition 2. In the model $R$, the optimal prices and showroom service are shown as

$$
\begin{aligned}
& p_{d}^{R^{*}}=\frac{\alpha \beta \rho+(1-\alpha)\left(2 \beta+2 \rho+\beta \rho^{2}\right)+\left(2-\beta^{2}\right) \alpha-c M}{4-\beta^{2} \rho^{2}-4 \beta^{2}-4 \beta \rho}+\frac{\left(2-\beta^{2}-\beta \rho\right)(c+r \phi)}{\left(4-\beta^{2} \rho^{2}-4 \beta^{2}-4 \beta \rho\right)(1-r)}, \\
& p_{r}^{R^{*}}=\frac{4-4 \alpha+2 \alpha \beta-2 \beta^{2} c-\beta^{2} \rho^{2} c-4 \beta \rho c}{4-\beta^{2} \rho^{2}-4 \beta^{2}-4 \beta \rho}+\frac{2 \beta(c+r \phi)}{\left(4-\beta^{2} \rho^{2}-4 \beta^{2}-4 \beta \rho\right)(1-r)}, \\
& e^{R^{*}}=\frac{(\beta \rho+2)\left(2-2 \alpha+\beta^{2} c+\alpha \beta-2 c\right)}{4-\beta^{2} \rho^{2}-4 \beta^{2}-4 \beta \rho}+\frac{\beta(\beta \rho+2)(c+r \phi)}{\left(4-\beta^{2} \rho^{2}-4 \beta^{2}-4 \beta \rho\right)(1-r)},
\end{aligned}
$$

where $M=2 \rho+\beta^{3}+\beta \rho^{2}+\beta^{2} \rho$. 
Proof. The proof is given in Appendix B.

$$
\begin{aligned}
& D_{d}^{R^{*}}=\frac{(1-\alpha)\left(2 \beta+2 \rho+\beta \rho^{2}\right)+\left(2-\beta^{2}-\beta \rho^{2}\right) \alpha-c M}{4-\beta^{2} \rho^{2}-4 \beta^{2}-4 \beta \rho}+\frac{(c+r \phi) N}{\left(4-\beta^{2} \rho^{2}-4 \beta^{2}-4 \beta \rho\right)(1-r)}, \\
& D_{r}^{R^{*}}=\left(2-\beta^{2}\right) \frac{\left(2-2 \alpha-2 c+\alpha \beta+\beta^{2} c\right)(1-r)+\beta(c+r \phi)}{\left(4-\beta^{2} \rho^{2}-4 \beta^{2}-4 \beta \rho\right)(1-r)}, \\
& D_{s}^{R^{*}}=D_{d}^{R^{*}}+D_{r}^{R^{*}}, \\
& \Pi_{d}^{R^{*}}=\frac{\left[\left(F+\beta\left(2-2 \alpha-\alpha \beta+\rho^{2}\right)-\rho E\right)(1-r)+(c+r \phi) N\right]^{2}}{\left(4-\beta^{2} \rho^{2}-4 \beta^{2}-4 \beta \rho\right)^{2}(1-r)}, \\
& \Pi_{r}^{R^{*}}=\frac{\left[\left(2-2 \alpha-2 c+\alpha \beta+\beta^{2} c\right)(1-r)+\beta(c+r \phi)\right]^{2}}{\left(4-\beta^{2} \rho^{2}-4 \beta^{2}-4 \beta \rho\right)(1-r)^{2}}, \\
& \Pi_{s}^{R^{*}}=\Pi_{d}^{R^{*}}+\Pi_{r}^{R^{*}},
\end{aligned}
$$

where $\quad N=3 \beta^{2}+3 \beta \rho+\beta^{2} \rho^{2}-2, \quad E=2 \alpha+\beta \rho c+\beta^{2} c+$ $\alpha \beta \rho+\alpha \beta$, and $F=2 \alpha+2 \rho-2 \rho c-\beta^{3} c$.

4.2. Online-Led Game. In the online-led game, the online retailer acts as the leader and the online retailer acts as the follower. The scenarios with NSS and SS strategies are investigated, respectively.

4.2.1. Model ND (Strategy NSS). In the model ND, the offline retailer adopts strategy NSS; that is, $e=0$. The online retailer firstly decides the retail price $p_{d}^{N D}$, and then the offline retailer determines the retail price $p_{r}^{N D}$. The optimal model is formulated as

$$
\max _{p_{d}^{N D}} \Pi_{d}^{N D}=\left[(1-r) p_{d}^{N D}-c-r \phi\right]\left(\alpha-p_{d}^{N D}+\beta p_{r}^{N D}\right)
$$

s.t. $\max _{p_{r}^{N D}} \Pi_{r}^{N D}=\left(p_{r}^{N D}-c\right)\left(1-\alpha-p_{r}^{N D}+\beta p_{d}^{N D}\right)$.

Similar to the solving process of model $N R$, the optimal results for the model $N D$ can be obtained using the reverse induction method, which are shown in Proposition 3.

Proposition 3. In the model ND, the optimal prices are shown as $p_{d}^{N D *}=\left((2 \alpha+\beta c+\beta(1-\alpha)) /\left(2\left(2-\beta^{2}\right)\right)\right)+((c+$ $r \phi) / 2(1-r))$ and $p_{r}^{N D *}=\left(\left(\left(4-\beta^{2}\right)(c+1-\alpha)+2 \alpha \beta\right) /\right.$ $\left.\left(4\left(2-\beta^{2}\right)\right)\right)+((\beta(c+r \phi)) /(4(1-r)))$.

And thus, the optimal demands and profits are given as

$$
\begin{aligned}
& D_{d}^{N D^{*}}=\frac{2 \alpha+\beta c+\beta(1-\alpha)}{4}+\frac{\left(\beta^{2}-2\right)(c+r \phi)}{4(1-r)}, \\
& D_{r}^{N D^{*}}=\frac{\beta(c+r \phi)}{4(1-r)}+\frac{\left(4-\beta^{2}\right)(1-\alpha)+2 \alpha \beta+\left(3 \beta^{2}-4\right) c}{4\left(2-\beta^{2}\right)}, \\
& D_{s}^{N D^{*}}=D_{d}^{N D^{*}}+D_{r}^{N D^{*}}, \\
& \Pi_{d}^{N D^{*}}=\frac{\left[(2 \alpha+\beta c+\beta-\beta \alpha)(1-r)+\left(\beta^{2}-2\right)(c+r \phi)\right]^{2}}{8\left(2-\beta^{2}\right)(1-r)}, \\
& \Pi_{r}^{N D^{*}}=\frac{\left[\left(4-4 \alpha+3 \beta^{2} c-4 c+\beta^{2} \alpha-\beta^{2}+2 \alpha \beta\right)(1-r)+\beta\left(2-\beta^{2}\right)(c+r \phi)\right]^{2}}{16\left(2-\beta^{2}\right)^{2}(1-r)^{2}}, \\
& \Pi_{s}^{N D^{*}}=\Pi_{d}^{N D^{*}}+\Pi_{r}^{N D^{*}} .
\end{aligned}
$$


4.2.2. Model D (Strategy SS). In the model $D$, the offline retailer implements strategy $\mathrm{SS}$; that is, $e^{D}>0$. The online retailer firstly decides the retail price $p_{d}^{D}$, and then the offline retailer decides the retail price $p_{r}^{D}$ and showroom service $e^{D}$. The optimal model is formulated as

$$
\max _{p_{d}^{D}} \Pi_{d}^{D}=\left[(1-r) p_{d}^{D}-c-r \phi\right]\left(\alpha-p_{d}^{D}+\beta p_{r}^{D}+\rho e^{D}\right)
$$

s.t. $\max _{p_{r}^{D}, e^{D}} \Pi_{r}^{D}=\left(p_{r}^{D}-c\right)\left(1-\alpha-p_{r}^{D}+\beta p_{d}^{D}+e^{D}\right)-\frac{1}{2} e^{D 2}$.
Similar to the solving process of model $N D$, the optimal results in the model $D$ can be obtained by using the reverse induction method, which are shown in Proposition 4.

Proposition 4. In the model D, the optimal prices and showroom service are shown as

$$
\begin{aligned}
& p_{d}^{D^{*}}=\frac{(\beta+\rho)(1-\alpha)+\alpha-\rho c}{2\left(1-\beta^{2}-\beta \rho\right)}+\frac{c+r \phi}{2(1-r)}, \\
& p_{r}^{D^{*}}=\frac{\left(2-\beta^{2}-\beta \rho\right)(1-\alpha)+\beta(\alpha-\rho c)}{2\left(1-\beta^{2}-\beta \rho\right)}+\frac{\beta(c+r \phi)}{2(1-r)}, \\
& e^{D^{*}}=\frac{\left(2-\beta^{2}-\beta \rho\right)(1-\alpha)+c\left(2 \beta^{2}+\beta \rho-2\right)+\alpha \beta}{2\left(1-\beta^{2}-\beta \rho\right)}+\frac{\beta(c+r \phi)}{2(1-r)} .
\end{aligned}
$$

Thus, the optimal demands and profits are given as

$$
\begin{aligned}
& D_{d}^{D^{*}}=\frac{(\beta+\rho)(1-\alpha)+\alpha-\rho c}{2}+\frac{\left(\beta^{2}+\beta \rho-1\right)(c+r \phi)}{2(1-r)}, \\
& D_{r}^{D^{*}}=\frac{\left(2-\beta^{2}-\beta \rho\right)(1-\alpha)+2 c\left(\beta^{2}-1\right)+\beta(\alpha+\rho c)}{2\left(1-\beta^{2}-\beta \rho\right)}+\frac{\beta(c+r \phi)}{2(1-r)}, \\
& D_{s}^{D^{*}}=D_{d}^{D^{*}}+D_{r}^{D^{*}}, \\
& \Pi_{d}^{D^{*}}=\frac{\left[(\beta+\rho)(1-\alpha)(1-r)+(\alpha-\rho c)(1-r)+\left(\beta^{2}+\beta \rho-1\right)(c+r \phi)\right]^{2}}{4(1-r)\left(1-\beta^{2}-\beta \rho\right)}, \\
& \Pi_{r}^{D^{*}}=\frac{\left[\left(2-\beta^{2}-\beta \rho\right)(1-\alpha)(1-r)+2 c\left(\beta^{2}-1\right)(1-r)+\beta(\alpha+\rho c)(1-r)+\left(1-\beta^{2}-\beta \rho\right)(c+r \phi)\right]^{2}}{8(1-r)^{2}\left(1-\beta^{2}-\beta \rho\right)^{2}}, \\
& \Pi_{s}^{D^{*}}=\Pi_{d}^{D^{*}}+\Pi_{r}^{D^{*}} .
\end{aligned}
$$

4.3. Nash Game. In this subsection, the online and offline retailers simultaneously determine the retail price and showroom service. The scenarios with strategies NSS and SS are explored, respectively.

4.3.1. Model NN (Strategy NSS). In the model NN, the offline retailer adopts the NSS strategy; that is, $e=0$. The online retailer decides the retail price $p_{d}^{N N}$, and the offline retailer simultaneously determines the retail price $p_{r}^{N N}$. The optimal model is formulated as

$$
\begin{aligned}
& \max _{p_{d}^{N N}} \Pi_{d}^{N N}=\left[(1-r) p_{d}^{N N}-c-r \phi\right]\left(\alpha-p_{d}^{N N}+\beta p_{r}^{N N}\right), \\
& \max _{p_{r}^{N N}} \Pi_{r}^{N N}=\left(p_{r}^{N N}-c\right)\left(1-\alpha-p_{r}^{N N}+\beta p_{d}^{N N}\right) .
\end{aligned}
$$


The optimal results in the model $N N$ can be obtained by using the reverse induction method, which are shown in Proposition 5.

Proposition 5. In the model $N N$, the optimal prices are shown as $p_{d}^{N N^{*}}=(((\beta-\beta \alpha+2 \alpha+\beta c)(1-r)+2(c+r \phi)) /$ $\left.\left((1-r)\left(4-\beta^{2}\right)\right)\right)$ and $p_{r}^{N N^{*}}=(((2-2 \alpha+2 c+\beta c)(1-r)$ $\left.+\beta(c+r \phi)) /\left((1-r)\left(4-\beta^{2}\right)\right)\right)$

Proof. The proof is given in Appendix C.

Thus, the optimal demands and profits are given as

$$
\begin{aligned}
D_{d}^{N N^{*}} & =\frac{(\beta-\beta \alpha+2 \alpha+\beta c)(1-r)+\left(\beta^{2}-2\right)(c+r \phi)}{(1-r)\left(4-\beta^{2}\right)}, \\
D_{r}^{N N^{*}} & =\frac{\left(2-2 \alpha-2 c+\beta \alpha+\beta^{2} c\right)(1-r)+\beta(c+r \phi)}{(1-r)\left(4-\beta^{2}\right)}, \\
D_{s}^{N N^{*}} & =D_{d}^{N N^{*}}+D_{r}^{N N^{*}}, \\
\Pi_{d}^{N N^{*}} & =\frac{\left[(\beta-\beta \alpha+2 \alpha+\beta c)(1-r)+\left(\beta^{2}-2\right)(c+r \phi)\right]^{2}}{(1-r)(2+\beta)^{2}(2-\beta)^{2}}, \\
\Pi_{r}^{N N^{*}} & =\frac{\left[\left(2-2 \alpha-2 c+\beta \alpha+\beta^{2} c\right)(1-r)+\beta(c+r \phi)\right]^{2}}{(1-r)^{2}(2+\beta)^{2}(2-\beta)^{2}}, \\
\prod_{s}^{N N^{*}} & =\prod_{d}^{N N^{*}}+\prod_{r}^{N N^{*}} .
\end{aligned}
$$

4.3.2. Model N (Strategy SS). In the model $N$, the offline retailer offers offline showroom service; that is, $e^{N}>0$. The online retailer determines the retail price $p_{d}^{N}$, and the offline retailer simultaneously sets the retail price $p_{r}^{N}$ and showroom service $e^{N}$. The optimal model is formulated as

$$
\begin{gathered}
\max _{p_{d}^{D}} \Pi_{d}^{N}=\left[(1-r) p_{d}^{N}-c-r \phi\right]\left(\alpha-p_{d}^{N}+\beta p_{r}^{N}+\rho e^{N}\right), \\
\max _{p_{r}^{N}, e^{N}} \Pi_{r}^{N}=\left(p_{r}^{N}-c\right)\left(1-\alpha-p_{r}^{N}+\beta p_{d}^{N}+e^{N}\right)-\frac{1}{2} e^{N 2} .
\end{gathered}
$$

The optimal results in the model $N$ can be obtained by using the reverse induction, which are shown in Proposition 6.

Proposition 6. In the model $N$, the optimal prices and showroom service are shown as

$$
\begin{aligned}
& p_{d}^{N^{*}}=\frac{(\beta-\alpha \beta+\alpha-\alpha \rho+\rho-\rho c)(1-r)+c+r \phi}{(1-r)\left(2-\beta^{2}-\beta \rho\right)}, \\
& p_{r}^{N^{*}}=\frac{(2+\alpha \beta-2 \alpha-\beta \rho c)(1-r)+\beta(c+r \phi)}{(1-r)\left(2-\beta^{2}-\beta \rho\right)}, \\
& e^{N^{*}}=\frac{\left(2-2 \alpha-2 c+\alpha \beta+\beta^{2} c\right)(1-r)+\beta(c+r \phi)}{(1-r)\left(2-\beta^{2}-\beta \rho\right)} .
\end{aligned}
$$

Proof. The proof is given in Appendix D.

Thus, the optimal demands and profits are given as

$$
\begin{aligned}
& D_{d}^{N^{*}}=\frac{(\beta-\alpha \beta+\alpha-\alpha \rho+\rho-\rho c)(1-r)+\left(\beta^{2}+\beta \rho-1\right)(c+r \phi)}{(1-r)\left(2-\beta^{2}-\beta \rho\right)}, \\
& D_{r}^{N^{*}}=\frac{\left(2-2 \alpha-2 c+\alpha \beta+\beta^{2} c\right)(1-r)+\beta(c+r \phi)}{(1-r)\left(2-\beta^{2}-\beta \rho\right)}, \\
& D_{s}^{N^{*}}=D_{d}^{N^{*}}+D_{r}^{N^{*}}, \\
& \Pi_{d}^{N^{*}}=\frac{\left[(\beta-\alpha \beta+\alpha-\alpha \rho+\rho-\rho c)(1-r)+\left(\beta^{2}+\beta \rho-1\right)(c+r \phi)\right]^{2}}{(1-r)\left(2-\beta^{2}-\beta \rho\right)^{2}}, \\
& \Pi_{r}^{N^{*}}=\frac{\left[\left(2-2 \alpha-2 c+\alpha \beta+\beta^{2} c\right)(1-r)+\beta(c+r \phi)\right]^{2}}{(1-r)^{2}\left(2-\beta^{2}-\beta \rho\right)^{2}}, \\
& \Pi_{s}^{N^{*}}=\Pi_{d}^{N^{*}}+\Pi_{r}^{N^{*}} .
\end{aligned}
$$




\section{Comparative Analysis of Equilibrium Results}

By comparing the equilibrium results in Propositions 1-6, the following conclusions can be drawn.

Firstly, the impacts of the showrooming effect are given in Propositions 7 and 8.

Proposition 7. (1) $\left(\partial p_{j}^{i *} / \partial \rho\right)>0$; (2) $\left(\partial e^{i *} / \partial \rho\right)>0$; $\left(\partial D_{j}^{i *} / \partial \rho\right)>0, i=\{D, R, N\}$ and $j=\{d, r\}$.

Proof. The proof is given in Appendix E.

From the perspective of showroom service, Proposition 7 indicates that the showrooming effect caused by offering offline showroom service can help online and offline retailers to attract more new consumers under different power structures, thereby motivating the offline retailer to increase the service level, so as to achieve a win-win situation. Specifically, with the increasing of the intensity of showrooming effect, the retail prices of online and offline channels will be increased by retailers. This implies that when there exists a showrooming effect, retailers can increase retail prices to obtain more profits, but the market shares of the two channels are enhanced. The reason behind this is that offline showroom service can stimulate more potential consumers. As a result, it can be suggested that online and offline retailers use advertising and other methods to enhance the intensity of the showrooming effect to exploit more potential consumers.

Proposition 8. (1) $p_{j}^{N i^{*}}<p_{j}^{i^{*}}$; (2) $D_{l}^{N i^{*}}<D_{l}^{i^{*}}$; (3) $\Pi_{l}^{N i^{*}}<\Pi_{l}^{i^{*}}$, $i \in\{D, R, N\}, j \in\{d, r\}$, and $l \in\{d, r, s\}$.

Proof. The proof is given in Appendix F.

Proposition 8 shows that strategy SS is more beneficial for supply chain members and systems than strategy NSS. The offline retailer will implement strategy SS under different power structures. That is to say, the channel power structure will not affect the choice of showroom service strategy. Under the case with SS strategy, the retail prices of online and offline channels are increased, but the demands of two channels are also increased. It can be explained that the showrooming effect stimulates the needs of potential consumers. The profit brought by higher retail prices and demands is greater than the cost of investment for showroom service, so the profits of retailers and supply chain have been increased. As a result, we can derive that the SS strategy is very effective, which means that the offline showroom service can expand the market share and improve the operation efficiency of the supply chain. These findings are quite different from the previous conclusion that the showrooming effect will bring negative impacts (Li et al. [8]; Jing [27]; Mehra et al. [32]; Schneider and Zielke [35]). It can be suggested that no matter what kind of channel power structure, the offline retailers adopt the SS strategy, which is better for the whole supply chain. And the online retailer should cooperate with the offline retailer to improve consumers' recognition of products through advertising cooperation, so as to enhance the intensity of the showrooming effect.
Secondly, the impact of consumer return on the pricing and service strategies is given in Proposition 9.

Proposition 9. (1) $\left(\partial p_{j}^{N i^{*}} / \partial r\right)>0$ and $\left(\partial p_{j}^{i^{*}} / \partial r\right)>0$; $\left(\partial e^{i^{*}} / \partial r\right)>0, i \in\{D, R, N\}$ and $j \in\{d, r\}$.

Proof. The proof is given in Appendix G.

Proposition 9 shows that a higher consumer return rate will lead retailers to increase the retail price, which is not affected by channel power structure and showroom service strategy. Besides, it would encourage the offline retailer to improve the offline showroom service level. This implies that an increasing online consumer return rate also stimulates offline retailers to increase showroom service levels when the SS strategy is adopted under different channel power structures. An increasing online consumer return rate can stimulate online retailers to increase the retail price of the online channel; specifically, it also leads offline retailers to increase the retail price of the offline channel, so as to avoid excessive price competition between online and offline channels. As a result, we can derive that the consumer return will also have a negative impact on themselves. Therefore, in order to reduce the consumer return rate, the online and offline retailers should cooperate to heighten the intensity of the showrooming effect, and thus the offline retailer will increase the offline showroom service level.

\section{Numerical Analysis}

In order to comprehensively analyze the influence of the showrooming effect, consumer return, and power structure on offline and online retailers' decisions, the numerical studies are carried out. Following Li et al. [6] and Radhi and Zhang [41], according to above assumptions, the parameters are setting as $\alpha=0.6, \beta=0.4, c=0.05, s=0.01, c_{h}=0.02$, and $\phi=c_{h}-s=0.01$.

6.1. The Effect of Consumer Return on the Optimal Results. Since the consumer return rate is very small, we set $r \in[0,0.5]$ and $\rho=0.5$, and then we have the effect of consumer return rate on the decisions of online and offline retailers under different power structures, which are shown in Figures 2-6.

Figure 2 shows that an increasing online consumer return rate will encourage offline retailers to improve their showroom services to attract more potential consumers, which verifies the conclusion of Proposition 9. Besides, we can find that, comparing the online-led and Nash power structures, the offline-led power structure is most conducive to offline retailers to improve the showroom service level. From the perspective of improving showroom service level, the offline-lead power structure is the best, but the Nash power structure is the worst. That is to say, the dynamic game is more conducive to improve the showroom service than the static game. Consequently, it is suggested that the offline retailers as leaders can make the showrooming effect more effective. 


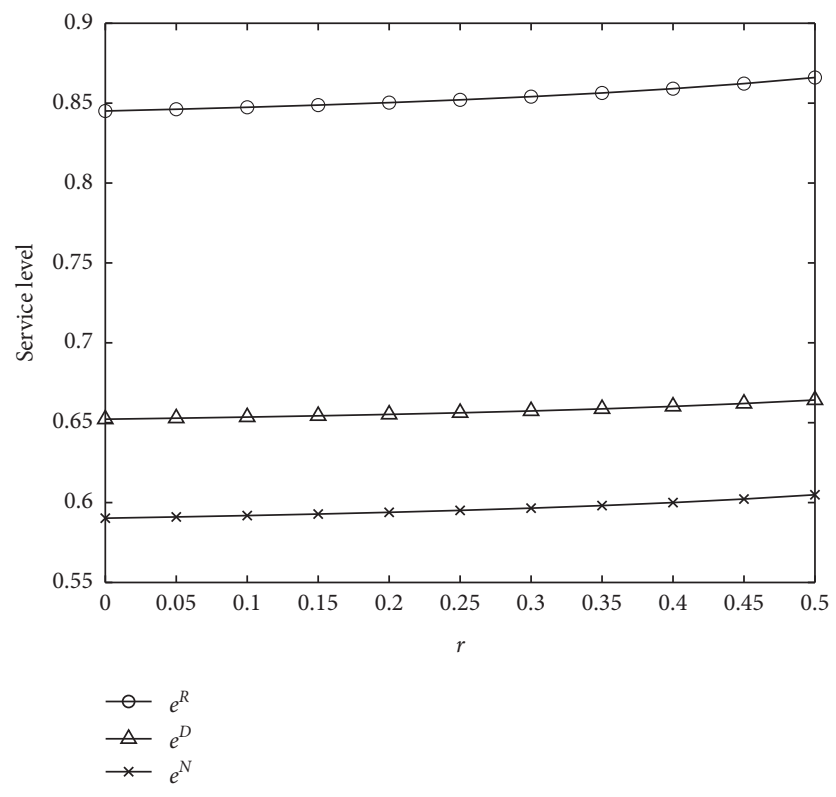

FIgURE 2: The effect of consumer return rate $r$ on showroom service level.
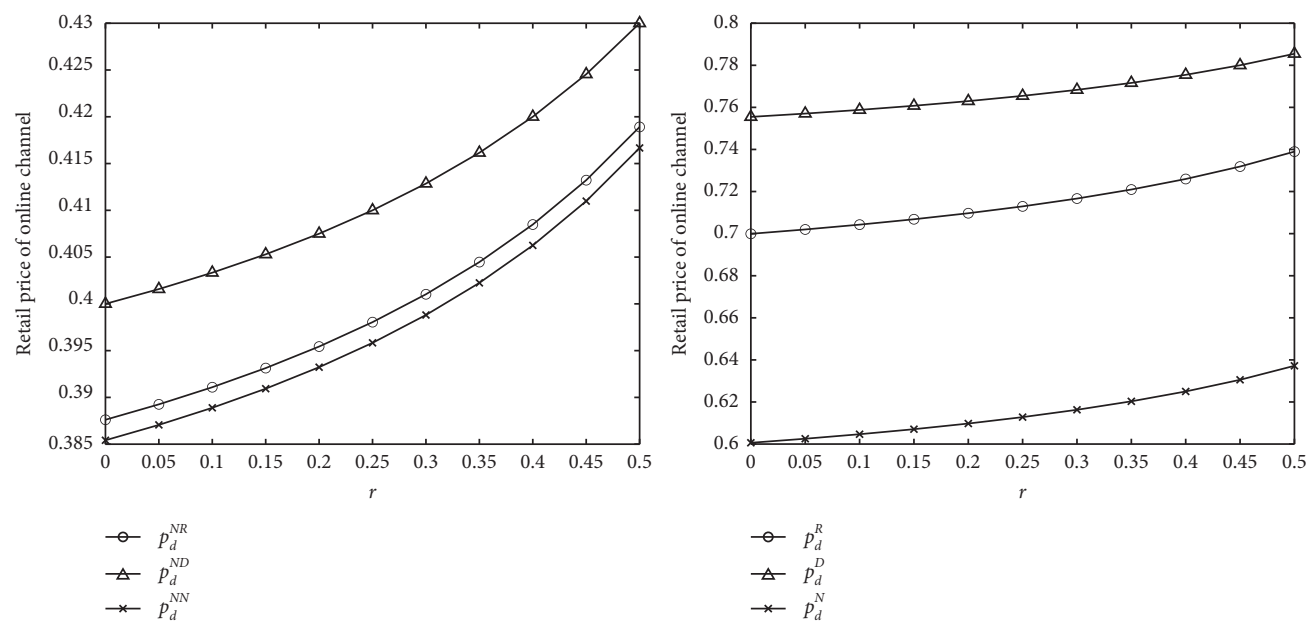

(a)
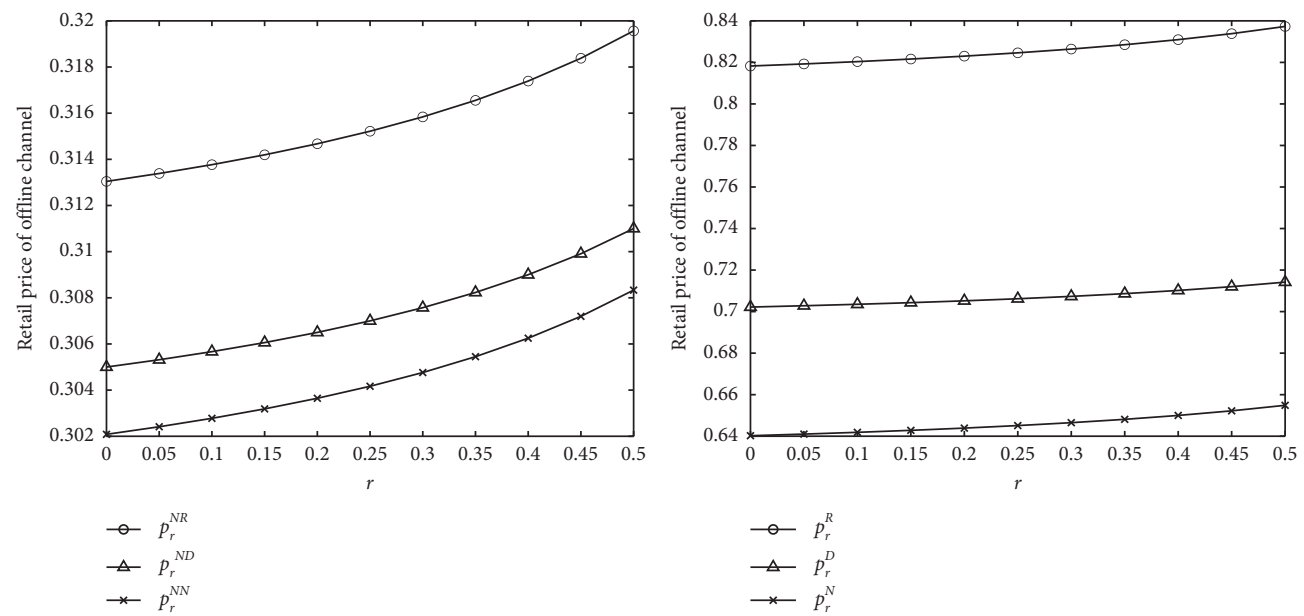

(b)

Figure 3: The effect of consumer return rate $r$ on retail price. (a) Retail price of the online channel. (b) Retail price of the offline channel. 

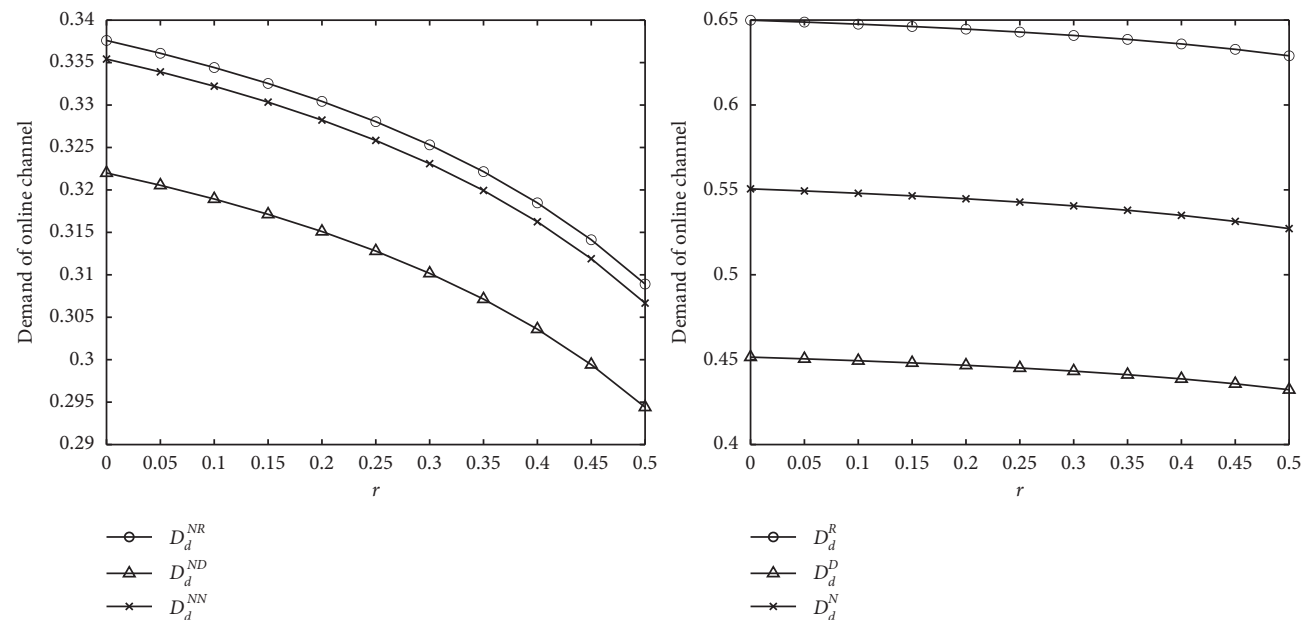

(a)
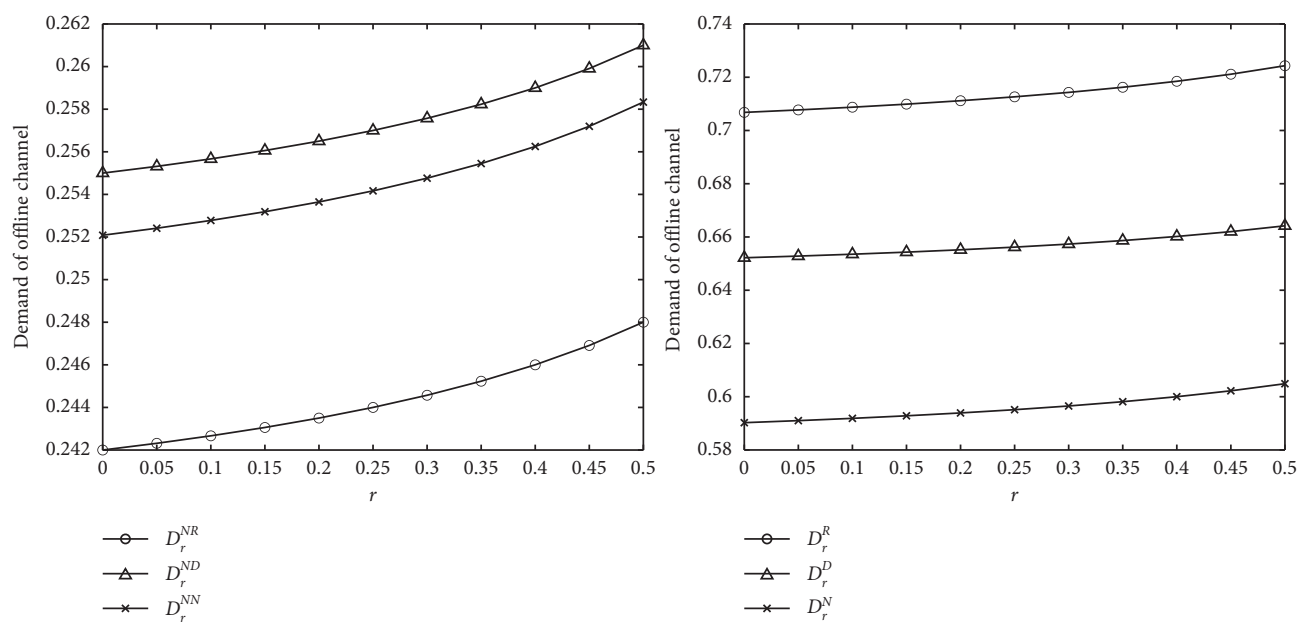

(b)

Figure 4: The effect of consumer return rate $r$ on demand. (a) Demand for online channel. (b) Demand for offline channel.
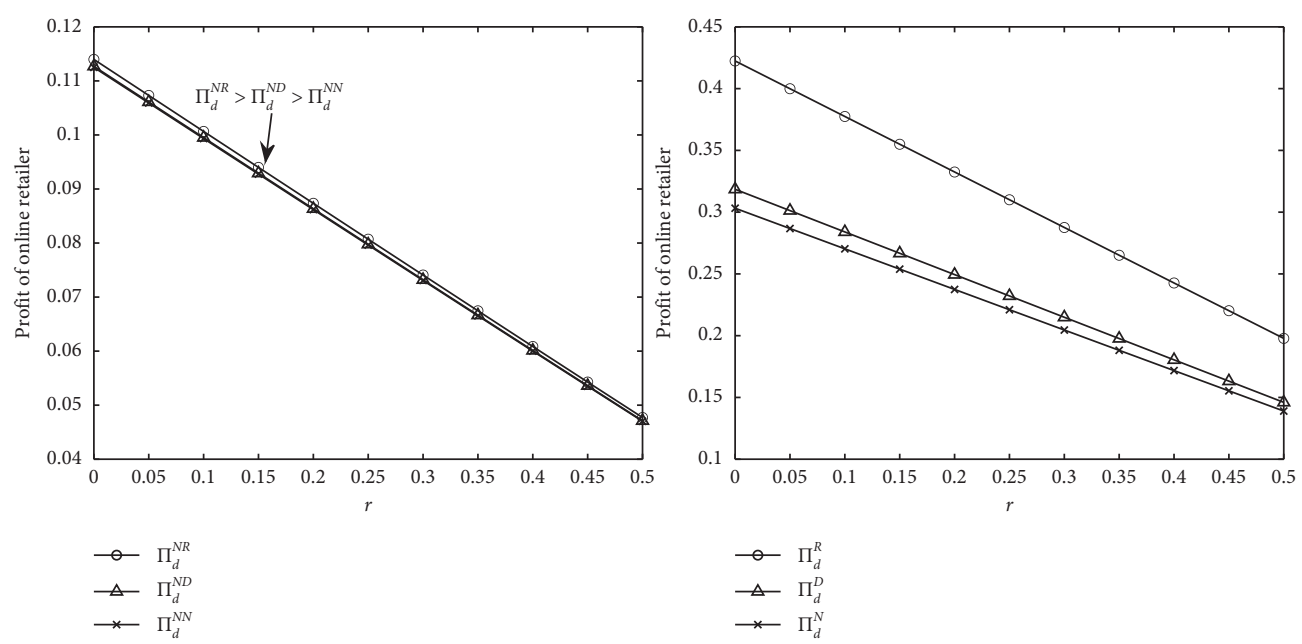

(a)

Figure 5: Continued. 

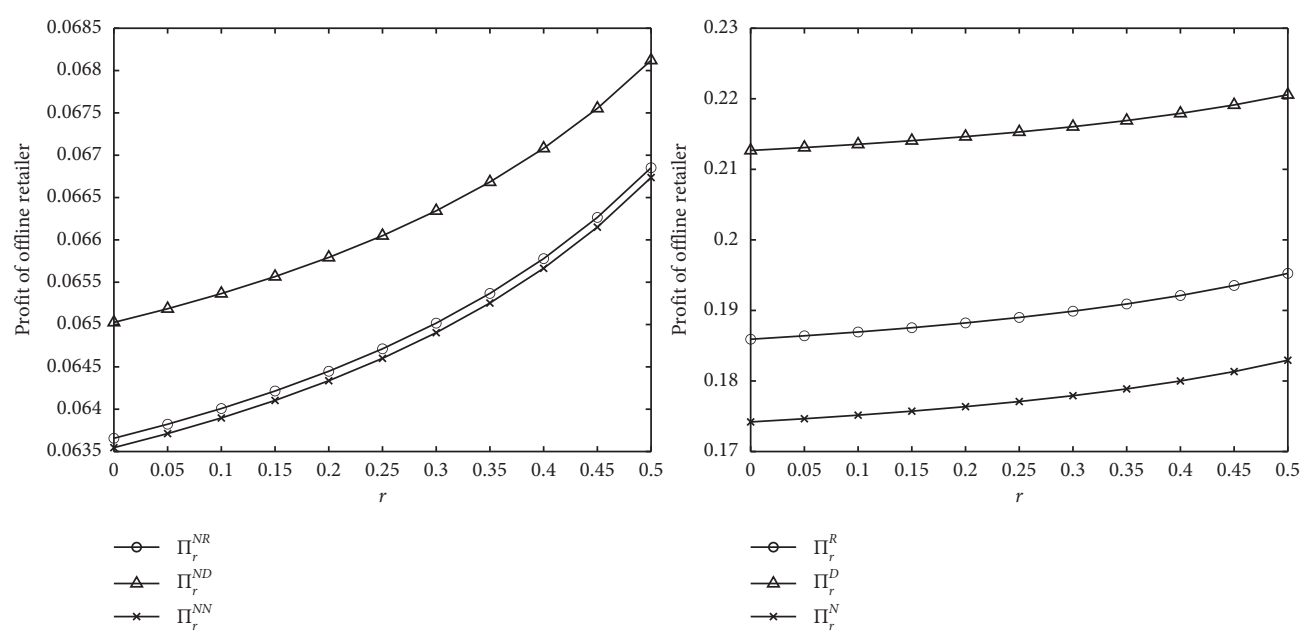

(b)

Figure 5: The effect of consumer return rate $r$ on profit. (a) The online retailer's profit. (b) The offline retailer's profit.

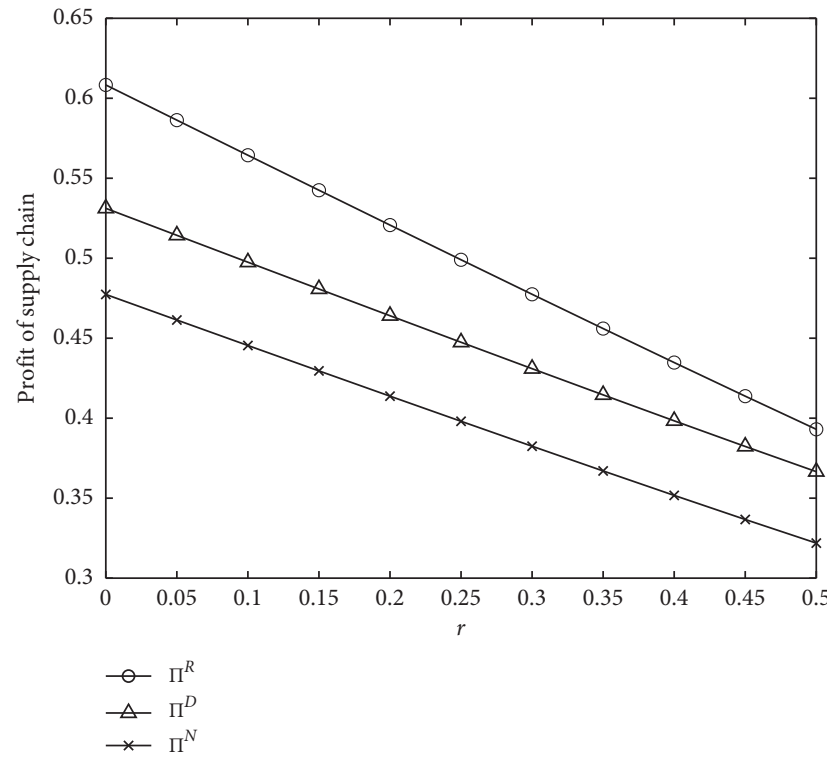

(a)

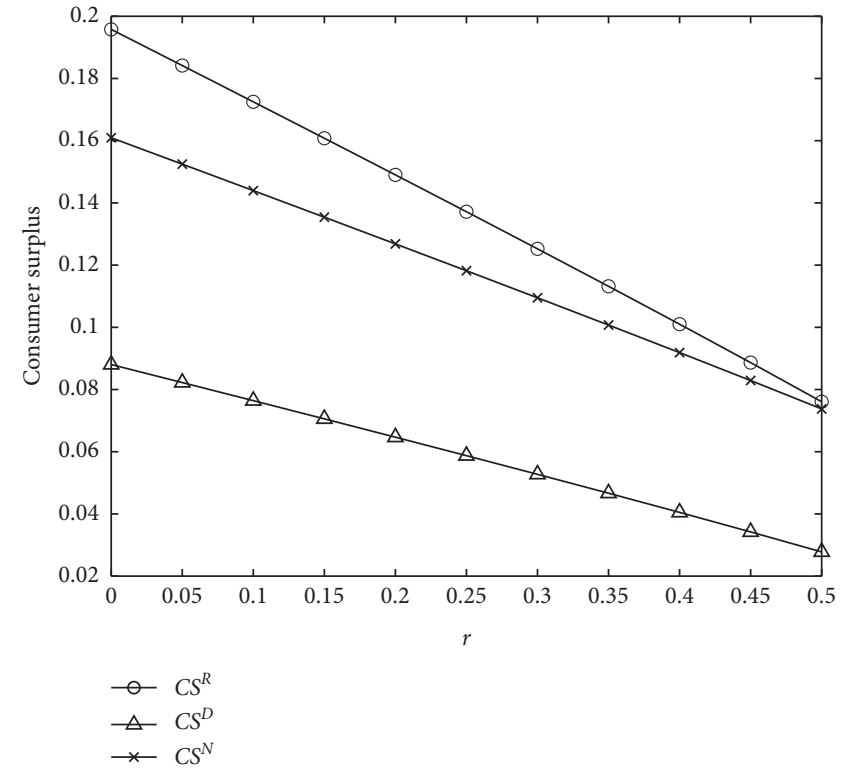

(b)

FIgURE 6: The effect of consumer return rate $r$ on (a) supply chain's profit and (b) consumer surplus.

From Figure 3, we can find that, no matter what kind of showroom service strategy and channel power structure is adopted, an increasing consumer return rate will lead online and offline retailers to increase the retail price of online and offline channels, respectively, which verifies the conclusions in Proposition 9. With the NSS or SS strategy, the retail price of the online channel under the online-led power structure is the highest, while the retail price of the offline channel under the offline-led power structure is the highest. However, the retail price of the online or offline channel under Nash power structure under two service strategies NSS and SS is the lowest. These confirm that the retailers could adjust the retail prices considering the power structure relationship between them. Therefore, it is suggested that the retailers can set appropriate retail prices, which are dependent on the bargaining powers of the online and offline retailers.

Figure 4 indicates that a higher consumer return rate will increase the demand for the offline channel but decrease the demand for online channel under NSS and SS strategies. This implies that an increasing online consumer return rate can stimulate more offline consumers to buy products through an offline channel. Whether the offline retailer adopts NSS or SS strategy, the demand for online channel under offline-led power structure is the highest. In other words, the offline-led power structure is more effective to expand market share of online channel. But under the NSS strategy, the online-led power structure is more effective, while under the SS strategy, the offline-led power structure is more effective. 


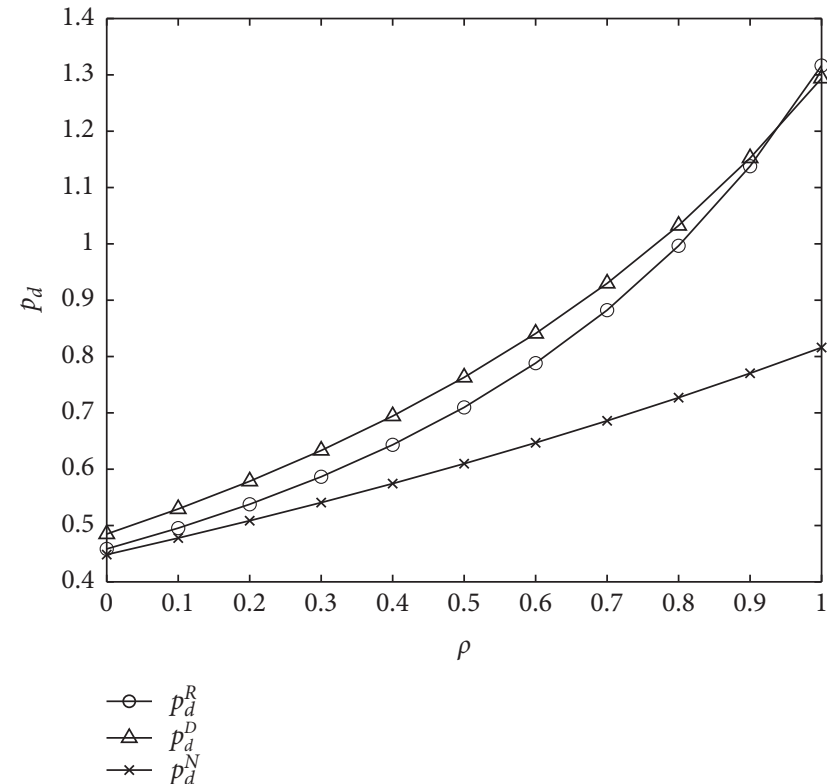

(a)

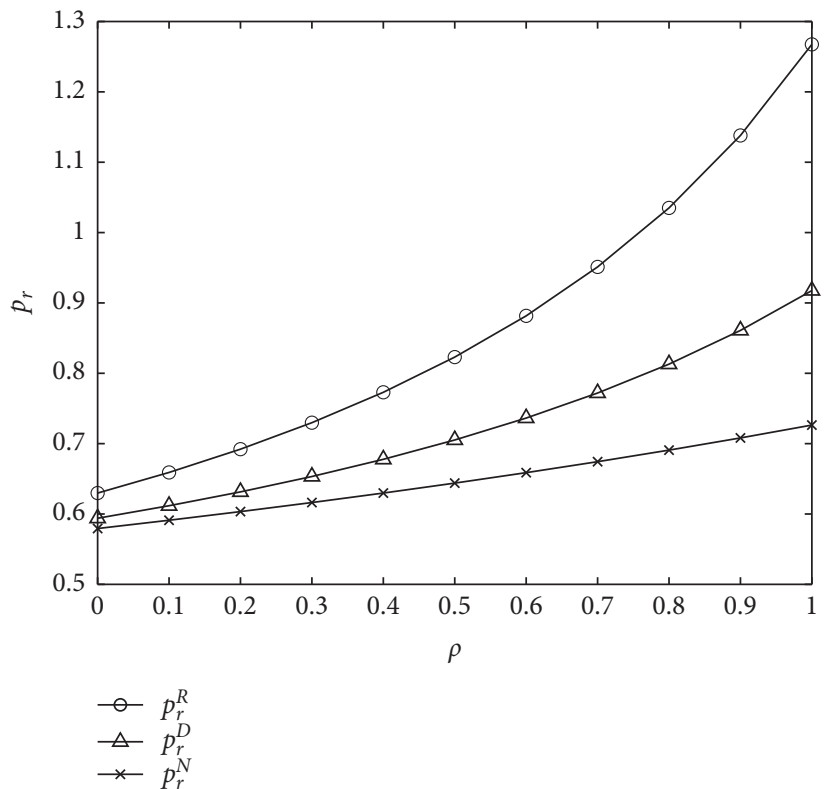

(b)

Figure 7: The effect of showrooming effect coefficient $\rho$ on retail price.

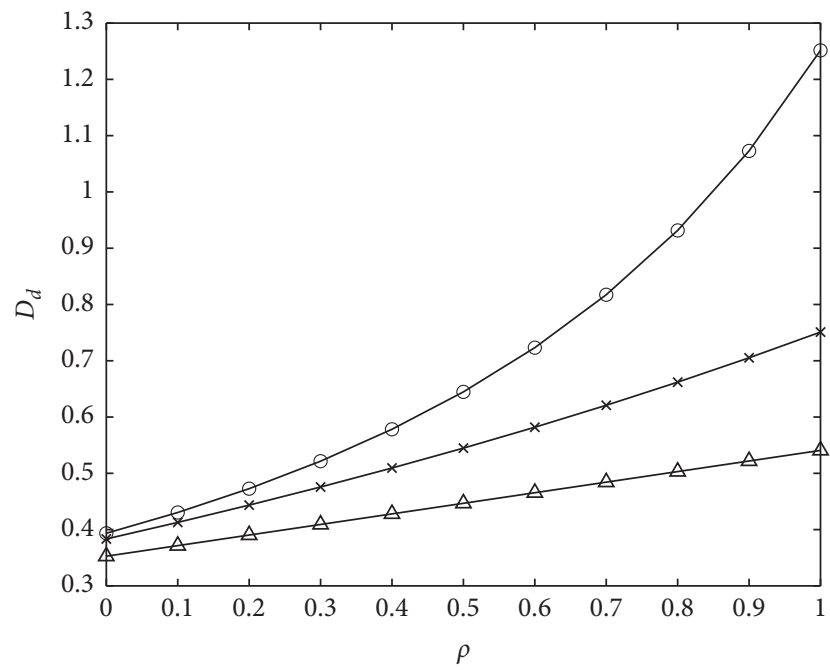
$-D_{d}^{R}$
$\triangle D_{d}^{D}$
$-\quad D_{d}^{N}$

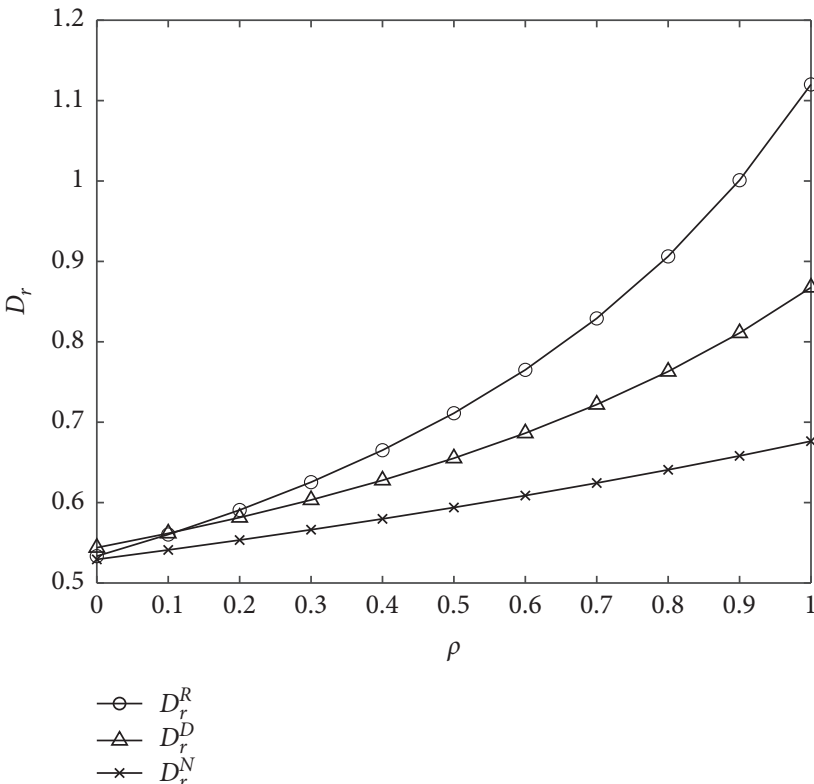

(b)

(a)

Figure 8: The effect of showrooming effect coefficient $\rho$ on demand.

From the perspective of expanding market share, the Nash power structure is often ineffective. Therefore, the offline-led power structure would be accepted by retailers to expand their market share.

Figure 5 indicates that a higher online consumer return rate will increase the profit of offline retailer but decrease the profit of online retailer. That is to say, consumer return is bad for online retailers. It is suggested that the online retailer should cooperate with the offline retailer to strengthen the intensity of the showrooming effect to mitigate the adverse impact of customer return. Besides, the offline-led power structure is always good for the online retailer, but onlineled is always good for the offline retailer. The Nash power structure is not always good for the online and offline 


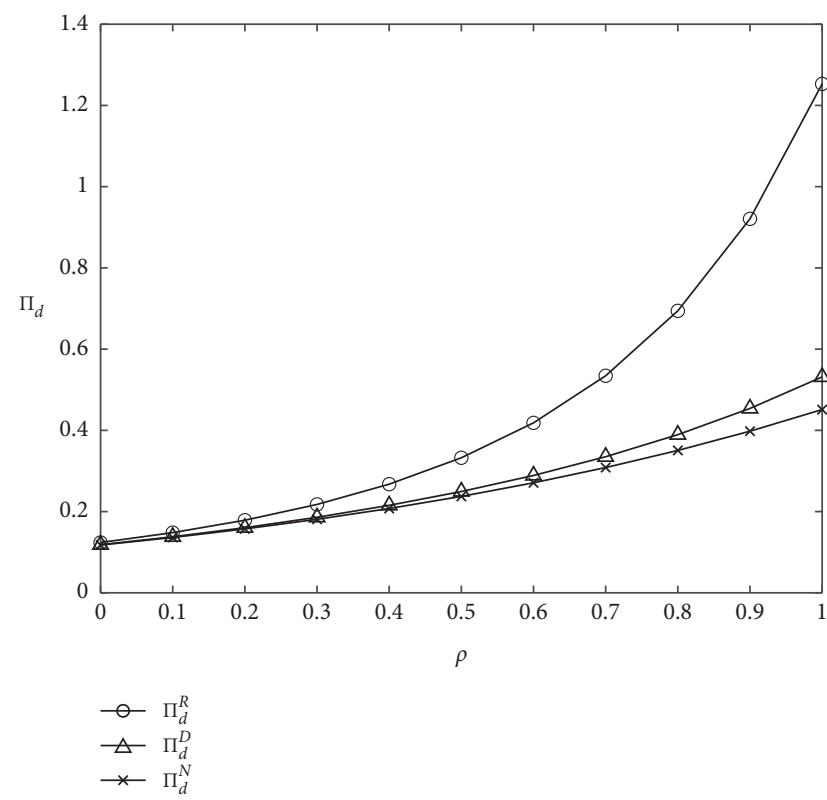

(a)

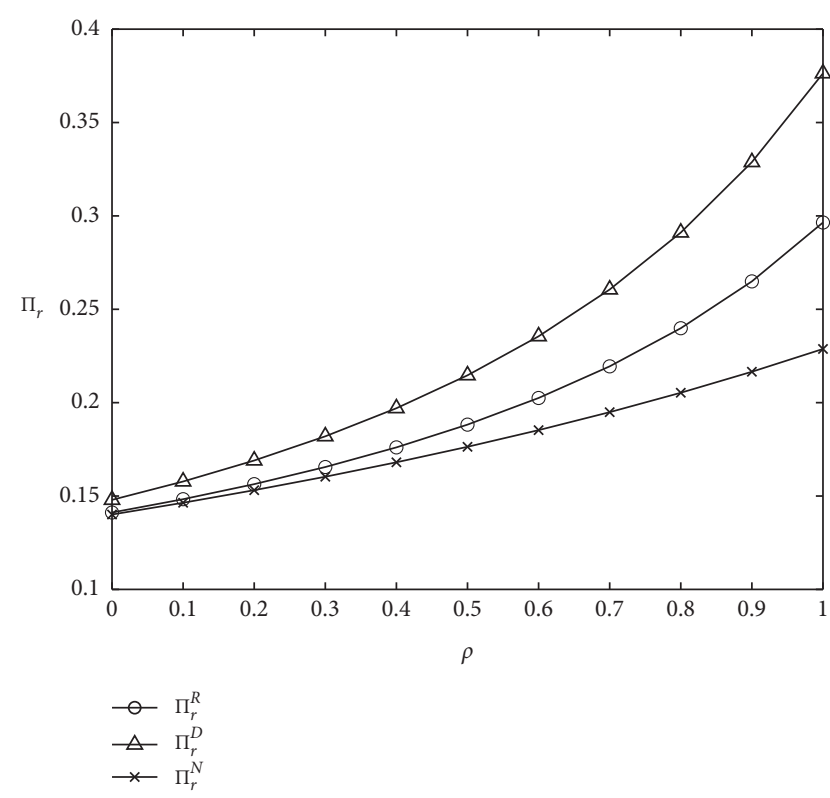

(b)

FIgURE 9: The effect of showrooming effect coefficient $\rho$ on profit.

retailers. The competitive situation can create higher profit than the Nash situation. As a result, the retailers can adopt a competitive channel structure to obtain more profit.

Since SS strategy is always implemented by offline retailers, we will analyze the impact of consumer return on the operation efficiency of the supply chain and consumer surplus in models $R, D$, and $N$. We first have the impact of consumer return on the supply chain's profit under different channel power structure, which is shown in Figure 6(a). Following Panda et al. [59], Liu et al. [60], Wang et al. [61], and Shi et al. [62], consumer surplus for products in a dualchannel supply chain can be calculated as $C S=\int_{\alpha+\beta p_{r}+\rho e-D_{d}}^{\alpha+\beta p_{r}+\rho e}(1-r)\left(\alpha-p_{d}+\beta p_{r}+\rho e\right) \mathrm{d} p_{d}+$ $\int_{1-\alpha+\beta p_{d}+e-D_{r}}^{1-\alpha+\beta p_{d}+e}\left(1-\alpha-p_{r}+\beta p_{d}+e\right) \mathrm{d} p_{r}$. The effect of consumer return on consumer surplus is illustrated in Figure 6(b).

From Figure 6, we can find that no matter what kind of showroom service strategy and channel power structure is adopted, a higher consumer return rate decreases the supply chain's profit and consumer surplus. This implies that consumer return is bad for the supply chain system and consumers. From the perspective of the supply chain system and consumers, the offline-led power structure is the best, but it will damage the benefit of the offline channel. Therefore, it is suggested that the online retailers should cooperate with offline retailers to implement an offline-led power structure to expand market share, so as to improve the supply chain operation efficiency.

However, in practice, with the rapid development of online shopping, more and more online retailers such as JD and Tmall have more and more power in recent years. This competitive online-led power structure not only is conducive to the operation of the whole supply chain but also harms the interests of consumers. Hence, it could be suggested that online and offline retailers should cooperate to reduce consumer returns and stimulate more potential consumers. Moreover, they should implement strategy SS and offline-led power structure, so as to improve consumer surplus and supply chain operation efficiency.

6.2. The Effect of Showrooming on Optimal Results. Since the SS strategy is always adopted by offline retailers, we just analyze the effect of showrooming effect on optimal results in models $R, D$, and $N$. In this part, we set $r=0.2$ and $\rho \in[0,1]$; thus, the effect of showrooming effect on retailer price, demand, and profit are illustrated in Figures 7-9.

Figure 7 indicates that a higher showrooming effect coefficient will increase the retail prices of online and offline channels. The reason behind this is that the showrooming effect motivates more potential consumers, which will bring retailers to increase their retail prices to obtain more benefits. When the showrooming effect coefficient is high enough, the retail prices of online and offline channels under offline-led power structure are the highest. But when the showrooming effect coefficient is small, the retail price of online channel under online-led power structure is the highest. Therefore, it is suggested that the retailers can set the appropriate value of retail prices, which is dependent on the bargaining powers of the online and offline retailers.

From Figure 8, we can find that a higher showrooming effect coefficient will increase the demands of online and offline channels. This implies that an increasing showrooming effect intensity can stimulate more consumers to buy products when the SS strategy is implemented. That is to say, strategy SS is more effective to expand market share. When the showrooming effect coefficient is so high, the 
demands for online and offline channels under offline-led power structure are the highest. But when the showrooming effect coefficient is small, the demand for offline channel under online-led power structure is the highest. Therefore, the offline-led power structure is more effective to expand market share, but the Nash power structure is the worst. The online retailers would be more likely to cooperate with the offline retailers to implement SS strategy and increase the intensity of the showrooming effect.

Figure 9 indicates that a higher showrooming effect coefficient will also increase the profits of online and offline retailers. This implies that the showrooming effect is always good for offline and online retailers. Besides, the offline-led power structure is the best choice for online retailers, while the online-led power structure is the best choice for offline retailers. The online and offline retailers all hate the Nash power structure. As a result, we can derive that the choice of channel power structure of online and offline retailers is inconsistent. But from the perspective of the supply chain system and consumers, the offline-led power structure is more effective. Therefore, it is suggested that the online retailers should cooperate with offline retailers to implement the offline-led power structure.

\section{Conclusions}

Considering online consumer return, this paper investigates the showroom service strategy and power structure for online and offline retailers. The online and offline retailers sell products to online and offline consumers, respectively. Combining two service strategies (NSS and SS) and three competition power structures, six models are constructed: $N R, R, N D, D, N N$, and $N$. Moreover, the effect of consumer return on the decisions of retailers is analyzed, and optimal showroom service strategy and power structure are put forward. The results show the following: (1) The offline showroom service can increase the retail prices, demands, and profits of online and offline retailers; as a result, SS strategy is optimal for retailers. Therefore, it is suggested that online retailers should cooperate with offline retailers to implement SS strategy and enhance the intensity of the showrooming effect. (2) Consumer return is beneficial for offline retailers, but it is not always good for the online retailers, supply chain system, and consumers. As a result, the online retailers are suggested to set an appropriate contract to motivate the offline retailers, which can help online retailers to respond to consumers' return. (3) The offline-led power structure is the best choice for online retailers, supply chain systems, and consumers, while the online-led power structure is the most beneficial for offline retailers. The Nash power structure is not always good for the retailers. The online retailers are suggested to cooperate with offline retailers to achieve a win-win situation through the effective use of offline-led power structure.

The findings show that firstly, although the offline showroom service needs high investment, this model helps the manager to attract more consumers by implementing the showroom service strategy because of the showrooming effect. Secondly, we put forward the method to alleviate the consumer return when the SS strategy is adopted. It is recommended that online retailer managers should cooperate with offline retailers to heighten the showrooming effect to relieve the consumer return. Lastly, it can be suggested that the firms should employ the offline-led power structure and thus improve the operation efficiency of the supply chain system. Therefore, the findings from the results assure that the retailers manage to give attention to the strategy SS and offline-led power structure. It is strongly recommended to revitalize the real economy of offline retailers and enhance the showrooming effect, and this is also consistent with the government's policy.

With the fierce competition between online and offline channels and online consumer return, the retailers have begun offline showroom service strategy programs to solve consumer return and explored what kind of power structure is better for themselves. Therefore, the showrooming effect has been rerecognized from the original negative impact. And then the firm's managers began to use the showrooming effect to implement the strategy SS effectively. Moreover, with the leading position of online channel becoming increasingly prominent, firms have to make sure that the online-led or Nash power structure is favorable. If the firms' managers put into the implementation showroom service strategy and offline-led power structure, then it leads to improving self-interest through effective response to consumer return for firms in future.

To implement showroom service strategy and power structure, there are limitations of two societal actors: consumers and enterprises. Awareness of the consumers about the showroom service level and power structure is the limitation. Because they pay less attention to the power structure and transfer demand from offline channel to online channel, consumers will return products they do not like. Enterprises need to balance the investment costs and benefits of showroom service. Moreover, the competitive power of online enterprises is more and more superior to that of offline enterprises because of the development of e-commerce. This will not be conducive to the operation of the supply chain system.

However, Nash and on-led power structures are not suitable for supply chain, and consumer return is always bad for supply chain and themselves. It is important to appreciate that enterprises implementing offline-led power structures to provide offline showroom service can be achievable, and it can bring more benefits for enterprises and consumers. In practice, the showroom service strategy has been implemented, which can not only expand market share but also solve consumer return problems. Besides, enterprises should strengthen cooperation to solve the problems in the supply chain, so as to achieve a win-win situation.

There are still some problems not considered in this paper. Firstly, this paper only considers the online consumer return behavior through the online channel. In reality, the consumers in the offline channel also return their unsatisfied products through the offline or online channel. Different ways of consumer return will be investigated in future research. Secondly, this paper explores the competition power structure between two retailers. There exist many 
competition retailers to sell products or they cooperate to provide products. It is worthwhile to investigate the different competition and cooperation relationships of retailers in supply chain. Finally, this paper proposes that the retailers need to cooperate to enhance the showrooming effect. Different cooperation modes will be investigated in future research.

\section{Appendix}

\section{A. Proof of Proposition 1}

In the model $N R$, since $\left(\partial^{2} \Pi_{d}^{N R} / \partial\left(p_{d}^{N R}\right)^{2}\right)=2(r-1)<0$, $\Pi_{d}^{N R}$ is concave on $p_{d}^{N R}$. It can be obtained from $\left(\partial \Pi_{d}^{N R} / \partial p_{d}^{N R}\right)=0$ that $p_{d}^{N R}=\left(\left(c+r \phi+\beta r\left(p_{r}^{N R}+\rho\right)+\alpha(1\right.\right.$ $-r)) /(2(1-r)))$. Substituting $p_{d}^{N R}$ into $\Pi_{r}^{N R}$, we obtain $\left(\partial^{2} \Pi_{r}^{N R} / \partial\left(p_{r}^{N R}\right)^{2}\right)=\beta^{2}-2<0 . \Pi_{r}^{N R}$ is concave on $p_{r}^{N R}$. It can be obtained from $\left(\partial \Pi_{r}^{N R} / \partial p_{r}^{N R}\right)=0$ that $p_{r}^{N i^{*}}=((\beta(c+$ $\left.r \phi)) /\left(2(1-r)\left(2-\beta^{2}\right)\right)\right)+\left((\beta \alpha+2(1-\alpha)) /\left(2\left(2-\beta^{2}\right)\right)\right)+$ $(c / 2)$. Substituting $p_{r}^{N R^{*}}$ into $p_{d}^{N R}$, we have $p_{d}^{N R^{*}}=(((4-$ $\left.\left.\left.\beta^{2}\right)(c+r \phi)\right) /\left(4(1-r)\left(2-\beta^{2}\right)\right)\right)+\left(\left(\left(4-\beta^{2}\right) \alpha+2 \beta(1-\alpha)\right) /\right.$ $\left.\left(4\left(2-\beta^{2}\right)\right)\right)+(\beta c / 4)$.

\section{B. Proof of Proposition 2}

In the model $R$, since $\left(\partial^{2} \Pi_{d}^{R} / \partial\left(p_{d}^{R}\right)^{2}\right)=2(r-1)<0, \Pi_{d}^{R}$ is concave on $p_{d}^{R}$. It can be obtained from $\left(\partial \Pi_{d}^{R} / \partial p_{d}^{R}\right)=0$ that $p_{d}^{R}=(c+r \phi / 2(1-r))+\left(\beta p_{r}^{R}+e \rho+\alpha / 2\right)$. Substituting $p_{d}^{R}$ into $\Pi_{r}^{R}$, we obtain $H=\left(\begin{array}{cc}\beta^{2}-2 & 1 \\ 1 & -1\end{array}\right)=1-\beta^{2}>0$. Therefore, $\Pi_{r}^{R}$ is strictly concave with respect to $p_{r}^{R}$ and $e^{R}$. It can be obtained from $\left(\partial \Pi_{r}^{R} / \partial p_{r}^{R}\right)=0$ and $\left(\partial \Pi_{r}^{R} / \partial e^{R}\right)=0$ that

$$
\begin{aligned}
& e^{R^{*}}=\frac{(\beta \rho+2)\left(2-2 \alpha+\beta^{2} c+\alpha \beta-2 c\right)}{4-\beta^{2} \rho^{2}-4 \beta^{2}-4 \beta \rho}+\frac{\beta(\beta \rho+2)(c+r \phi)}{\left(4-\beta^{2} \rho^{2}-4 \beta^{2}-4 \beta \rho\right)(1-r)}, \\
& p_{r}^{R^{*}}=\frac{4-4 \alpha+2 \alpha \beta-2 \beta^{2} c-\beta^{2} \rho^{2} c-4 \beta \rho c}{4-\beta^{2} \rho^{2}-4 \beta^{2}-4 \beta \rho}+\frac{2 \beta(c+r \phi)}{\left(4-\beta^{2} \rho^{2}-4 \beta^{2}-4 \beta \rho\right)(1-r)} .
\end{aligned}
$$

Substituting $e^{R *}$ and $p_{r}^{R *}$ into $p_{d}^{R}$, we have

$$
p_{d}^{R^{*}}=\frac{\alpha \beta \rho+(1-\alpha)\left(2 \beta+2 \rho+\beta \rho^{2}\right)+\left(2-\beta^{2}\right) \alpha-c M}{4-\beta^{2} \rho^{2}-4 \beta^{2}-4 \beta \rho}+\frac{\left(2-\beta^{2}-\beta \rho\right)(c+r \phi)}{\left(4-\beta^{2} \rho^{2}-4 \beta^{2}-4 \beta \rho\right)(1-r)}
$$

\section{Proof of Proposition 5}

Since $\quad\left(\partial^{2} \Pi_{d}^{N N} / \partial p_{d}^{N N 2}\right)=2(r-1)<0 \quad$ and $\quad\left(\partial^{2} \Pi_{r}^{N N} /\right.$ $\left.\partial p_{r}^{N N 2}\right)=-2<0, \Pi_{d}^{N N}$ or $\Pi_{r}^{N N}$ is concave on $p_{d}^{N N}$ or $p_{r}^{N N}$, respectively. It can be obtained from $\left(\partial \Pi_{d}^{N N} / \partial p_{d}^{N N}\right)=0$ and $\left(\partial \Pi_{r}^{N N} / \partial p_{r}^{N N}\right)=0$ that $p_{d}^{N N *}=(((\beta-\beta \alpha+2 \alpha+\beta c)(1-$ $\left.r)+2(c+r \phi)) /\left((1-r)\left(4-\beta^{2}\right)\right)\right)$ and $p_{r}^{N N^{*}}=(((2-2 \alpha+$ $\left.2 c+\beta c)(1-r)+\beta(c+r \phi)) /\left((1-r)\left(4-\beta^{2}\right)\right)\right)$.

\section{Proof of Proposition 6}

$$
\begin{aligned}
& p_{d}^{N^{*}}=\frac{(\beta-\beta \alpha+\alpha-\alpha \rho+\rho-\rho c)(1-r)+c+r \phi}{(1-r)\left(2-\beta^{2}-\beta \rho\right)}, \\
& p_{r}^{N^{*}}=\frac{(2+\beta \alpha-2 \alpha-\beta \rho c)(1-r)+\beta(c+r \phi)}{(1-r)\left(2-\beta^{2}-\beta \rho\right)}, \\
& e^{N^{*}}=\frac{\left(2-2 \alpha-2 c+\beta \alpha+\beta^{2} c\right)(1-r)+\beta(c+r \phi)}{(1-r)\left(2-\beta^{2}-\beta \rho\right)} .
\end{aligned}
$$

Since $\left(\partial^{2} \Pi_{d}^{N} / \partial p_{d}^{N 2}\right)=2(r-1)<0, \Pi_{d}^{N}$ is concave on $p_{d}^{N}$. The Hessian matrix of $\Pi_{r}^{N}$ is $H_{r}^{\Pi_{r}^{N}}=\left(\begin{array}{cc}\left(\partial^{2} \Pi_{r}^{N} / \partial p_{r}^{N 2}\right) & \left(\partial^{2} \Pi_{r}^{N} / \partial p_{r}^{N} e^{N}\right) \\ \left(\partial^{2} \Pi_{r}^{N} / \partial e^{N} p_{r}^{N}\right) & \left(\partial^{2} \Pi_{r}^{N} / \partial e^{N 2}\right)\end{array}\right)=\left(\begin{array}{cc}-2 & 1 \\ 1 & -1\end{array}\right)$ since $\left(\partial^{2} \Pi_{r}^{N} / \partial p_{r}^{N 2}\right)=-2<0$, and $H_{r}^{\Pi_{r}^{N}}=1>0$, and $\Pi_{r}^{N}$ is strictly concave with respect to $p_{r}^{N}$ and $e^{N}$. It can be obtained from $\left(\partial \Pi_{d}^{N} / \partial p_{d}^{N}\right)=0,\left(\partial \Pi_{r}^{N} / \partial p_{r}^{N}\right)=0$, and $\left(\partial \Pi_{r}^{N} / \partial e^{N}\right)=0$ that

\section{E. Proof of Proposition 7}

Since $0<\rho<\left(\left(2 \sqrt{2-\beta^{2}}-2\right) / \beta\right)$ and $0<c<((2-2 \alpha$ $\left.+\alpha \beta) /\left(2-2 \beta^{2}\right)\right)$, we have $4-\beta^{2} \rho^{2}-4 \beta^{2}-4 \beta \rho>0$, $2-2 \beta-2 \rho-\beta \rho-\beta \rho^{2}-\beta^{2}$, and $2-2 \alpha+\beta^{2} c+\alpha \beta-2 c>0$. Because $0<\beta<1,0<r<1$, and $0<\phi<1$, it can be easily verified that 
(1)

$$
\begin{aligned}
& \frac{\partial p_{d}^{R^{*}}}{\partial \rho}=\left(4+4 \beta \rho-\beta^{2} \rho^{2}-2 \beta^{3} \rho\right) \frac{\left(2-2 \alpha+\beta^{2} c+\alpha \beta-2 c\right)(1-r)+\beta(c+r \phi)}{\left(4-\beta^{2} \rho^{2}-4 \beta^{2}-4 \beta \rho\right)^{2}(1-r)}>0, \\
& \frac{\partial p_{r}^{R^{*}}}{\partial \rho}=4 \beta(\beta \rho+2) \frac{\left(2-2 \alpha+\beta^{2} c+\alpha \beta-2 c\right)(1-r)+\beta(c+r \phi)}{\left(4-\beta^{2} \rho^{2}-4 \beta^{2}-4 \beta \rho\right)^{2}(1-r)}>0, \\
& \frac{\partial p_{d}^{D^{*}}}{\partial \rho}=\frac{1+\alpha \beta-\alpha-c\left(1-\beta^{2}\right)}{2\left(\beta^{2}+\beta \rho-1\right)^{2}}>0, \\
& \frac{\partial p_{r}^{D^{*}}}{\partial \rho}=\frac{\beta\left[1+\alpha \beta-\alpha-c\left(1-\beta^{2}\right)\right]}{2\left(\beta^{2}+\beta \rho-1\right)^{2}}>0, \\
& \frac{\partial p_{d}^{N^{*}}}{\partial \rho}=\frac{\left(2-2 \alpha-2 c+\beta \alpha+\beta^{2} c\right)(1-r)+\beta(c+r \phi)}{(1-r)\left(2-\beta^{2}-\beta \rho\right)^{2}}>0, \\
& \frac{\partial p_{r}^{N^{*}}}{\partial \rho}=\frac{\beta\left[\left(2-2 \alpha-2 c+\beta \alpha+\beta^{2} c\right)(1-r)+\beta(c+r \phi)\right]}{(1-r)\left(2-\beta^{2}-\beta \rho\right)^{2}}>0 .
\end{aligned}
$$

(2)

$$
\begin{aligned}
& \frac{\partial e^{R^{*}}}{\partial \rho}=\beta\left(\beta^{2} \rho^{2}-4 \beta^{2}+4 \beta \rho+12\right) \frac{\left(2-2 \alpha+\beta^{2} c+\alpha \beta-2 c\right)(1-r)+\beta(c+r \phi)}{\left(4-\beta^{2} \rho^{2}-4 \beta^{2}-4 \beta \rho\right)^{2}(1-r)}>0, \\
& \frac{\partial e^{D^{*}}}{\partial \rho}=\frac{\beta\left[1+\alpha \beta-\alpha-c\left(1-\beta^{2}\right)\right]}{2\left(\beta^{2}+\beta \rho-1\right)^{2}}>0, \\
& \frac{\partial e^{N^{*}}}{\partial \rho}=\frac{\beta\left[\left(2-2 \alpha-2 c+\beta \alpha+\beta^{2} c\right)(1-r)+\beta(c+r \phi)\right]}{(1-r)\left(2-\beta^{2}-\beta \rho\right)^{2}}>0 .
\end{aligned}
$$

(3)

$$
\begin{aligned}
& \frac{\partial D_{d}^{R}}{\partial \rho}=\frac{\left[\left(2-2 \alpha-2 c+\alpha \beta+\beta^{2} c\right)(1-r)+\beta(c+r \phi)\right]\left(4+4 \beta \rho-\beta^{2} \rho^{2}-2 \beta^{3} \rho\right)}{(1-r)\left(4-4 \beta^{2}-4 \beta \rho-\beta^{2} \rho^{2}\right)^{2}}>0, \\
& \frac{\partial D_{r}^{R}}{\partial \rho}=\frac{2 \beta\left(2-\beta^{2}\right)(\beta \rho+2)\left[\left(2-2 \alpha-2 c+\alpha \beta+\beta^{2} c\right)(1-r)+\beta(c+r \phi)\right]}{(1-r)\left(4-4 \beta^{2}-4 \beta \rho-\beta^{2} \rho^{2}\right)^{2}}>0, \\
& \frac{\partial D_{d}^{D}}{\partial \rho}=\frac{(1-\alpha-c)(1-r)+\beta(c+r \phi)}{2(1-r)}>0,
\end{aligned}
$$




$$
\begin{aligned}
& \frac{\partial D_{r}^{D}}{\partial \rho}=\frac{\beta[1-\alpha-c+\beta(\alpha+c \beta)]}{2\left(1-\beta^{2}-\beta \rho\right)^{2}}>0, \\
& \frac{\partial D_{d}^{N}}{\partial \rho}=\frac{\left(2-2 \alpha-2 c+\alpha \beta+\beta^{2} c\right)(1-r)+\beta(c+r \phi)}{(1-r)\left(2-\beta^{2}-\beta \rho\right)^{2}}>0, \\
& \frac{\partial D_{r}^{N}}{\partial \rho}=\frac{\beta\left[\left(2-2 \alpha-2 c+\alpha \beta+\beta^{2} c\right)(1-r)+\beta(c+r \phi)\right]}{(1-r)\left(2-\beta^{2}-\beta \rho\right)^{2}}>0 .
\end{aligned}
$$

\section{F. Proof of Proposition 8}

Since $0<\rho<\left(\left(2 \sqrt{2-\beta^{2}}-2\right) / \beta\right)$ and $0<c<((2-2 \alpha+$ $\left.\alpha \beta) /\left(2-2 \beta^{2}\right)\right)$, we have $4-\beta^{2} \rho^{2}-4 \beta^{2}-4 \beta \rho>0,2-2 \beta-$
$2 \rho-\beta \rho-\beta \rho^{2}-\beta^{2}$, and $2-2 \alpha+\beta^{2} c+\alpha \beta-2 c>0$. Because $0<\beta<1,0<r<1$, and $0<\phi<1$, it can be easily verified that

(1)

$$
\begin{aligned}
p_{d}^{N R^{*}}-p_{d}^{R^{*}}= & \frac{\left(2-2 \alpha+\beta^{2} c+\alpha \beta-2 c\right)(1-r)+\beta(c+r \phi)}{4\left(2-\beta^{2}\right)(1-r)\left(4-\beta^{2} \rho^{2}-4 \beta^{2}-4 \beta \rho\right)}\left(\rho \beta^{2}-2 \beta-4 \rho\right)(\beta \rho+2)<0, \\
p_{r}^{N R^{*}}-p_{r}^{R^{*}}= & -\frac{\left(2-2 \alpha+\beta^{2} c+\alpha \beta-2 c\right)(1-r)+\beta(c+r \phi)}{4\left(2-\beta^{2}\right)(1-r)\left(4-\beta^{2} \rho^{2}-4 \beta^{2}-4 \beta \rho\right)}(\beta \rho+2)^{2}<0, \\
p_{d}^{N D^{*}}-p_{d}^{D^{*}=} & -\frac{\left(1+\alpha \beta-\alpha-c+\beta^{2} c\right)(\beta+2 \rho)}{2\left(2-\beta^{2}\right)\left(1-\beta^{2}-\beta \rho\right)}<0, \\
p_{r}^{N D^{*}}-p_{r}^{D^{*}=} & -\frac{\beta(c+r \phi)\left(2-3 \beta^{2}+\beta^{4}-2 \beta \rho+\beta^{3} \rho\right)}{4\left(2-\beta^{2}\right)(1-r)\left(1-\beta^{2}-\beta \rho\right)}, \\
& -\frac{\left(4-4 \alpha-4 c+2 \alpha \beta+3 \alpha \beta^{2}-\alpha \beta^{4}+\beta^{3} \rho-3 \beta^{2}+\beta^{4}-\beta^{4} c+2 \beta^{2} \alpha \rho-\beta^{3} \alpha \rho+\beta^{2} \rho c\right)(1-r)}{4\left(2-\beta^{2}\right)(1-r)\left(1-\beta^{2}-\beta \rho\right)}<0, \\
p_{d}^{N N^{*}}-p_{d}^{N^{*}=} & -\frac{\left(2-2 \alpha-2 c+\beta \alpha+\beta^{2} c\right)(1-r)+\beta(c+r \phi)}{(1-r)\left(2-\beta^{2}-\beta \rho\right)\left(4-\beta^{2}\right)}(\beta+2 \rho)<0, \\
p_{r}^{N N^{*}}-p_{r}^{N^{*}}= & -\frac{\left(2-2 \alpha-2 c+\beta \alpha+\beta^{2} c\right)(1-r)+\beta(c+r \phi)}{(1-r)\left(2-\beta^{2}-\beta \rho\right)\left(4-\beta^{2}\right)}(\beta \rho+2)<0 .
\end{aligned}
$$

(2)

$$
\begin{aligned}
& D_{d}^{N N^{*}}-D_{d}^{R^{*}}=-\frac{\left(2-2 \alpha+\beta^{2} c+\alpha \beta-2 c\right)(1-r)+\beta(c+r \phi)}{4\left(2-\beta^{2}\right)(1-r)\left(4-\beta^{2} \rho^{2}-4 \beta^{2}-4 \beta \rho\right)}\left(4 \rho-\rho \beta^{2}+2 \beta\right)(\beta \rho+2)<0, \\
& D_{r}^{N N^{*}}-D_{r}^{R^{*}}=-\frac{\left(2-2 \alpha+\beta^{2} c+\alpha \beta-2 c\right)(1-r)+\beta(c+r \phi)}{4\left(2-\beta^{2}\right)(1-r)\left(4-\beta^{2} \rho^{2}-4 \beta^{2}-4 \beta \rho\right)}(\beta \rho+2)^{2}<0,
\end{aligned}
$$




$$
\begin{aligned}
D_{s}^{N N^{*}}-D_{s}^{R^{*}=} & -\frac{\left(2-2 \alpha+\beta^{2} c+\alpha \beta-2 c\right)(1-r)+\beta(c+r \phi)}{4\left(2-\beta^{2}\right)(1-r)\left(4-\beta^{2} \rho^{2}-4 \beta^{2}-4 \beta \rho\right)}(\beta \rho+2)\left(4 \rho-\rho \beta^{2}+2 \beta+\beta \rho+2\right)<0, \\
D_{d}^{N D^{*}}-D_{d}^{D^{*}=} & -(\beta+2 \rho) \frac{\beta(c+r \phi)+(1-r)(1-\alpha-c)}{4(1-r)}<0, \\
D_{r}^{N D^{*}}-D_{r}^{D^{*}=} & -\frac{\beta(c+r \phi)\left(2-3 \beta^{2}+\beta^{4}-2 \beta \rho+\beta^{3} \rho\right)}{8\left(2-\beta^{2}\right)(1-r)\left(1-\beta^{2}-\beta \rho\right)} \\
& -\frac{\left(4-4 \alpha-4 c+2 \alpha \beta+3 \alpha \beta^{2}-\alpha \beta^{4}+\beta^{3} \rho-3 \beta^{2}+\beta^{4}-\beta^{4} c+2 \beta^{2} \alpha \rho-\beta^{3} \alpha \rho+\beta^{2} \rho c\right)(1-r)}{8\left(2-\beta^{2}\right)(1-r)\left(1-\beta^{2}-\beta \rho\right)}<0, \\
D_{s}^{N D^{*}}-D_{s}^{D^{*}=} & D_{d}^{N D *}-D_{d}^{D^{*}}+D_{r}^{N D^{*}}-D_{r}^{D^{*}}<0, \\
D_{d}^{N N^{*}}-D_{d}^{N^{*}}= & -\frac{\left(2-2 \alpha-2 c+\beta \alpha+\beta^{2} c\right)(1-r)+\beta(c+r \phi)}{(1-r)\left(2-\beta^{2}-\beta \rho\right)\left(4-\beta^{2}\right)}(\beta+2 \rho)<0, \\
D_{r}^{N N^{*}}-D_{r}^{N^{*}}= & -\frac{\left(2-2 \alpha-2 c+\beta \alpha+\beta^{2} c\right)(1-r)+\beta(c+r \phi)}{(1-r)\left(2-\beta^{2}-\beta \rho\right)\left(4-\beta^{2}\right)}(\beta \rho+2)<0, \\
D_{s}^{N N^{*}}-D_{s}^{R^{*}}= & -\frac{\left(2-2 \alpha-2 c+\beta \alpha+\beta^{2} c\right)(1-r)+\beta(c+r \phi)}{(1-r)\left(2-\beta^{2}-\beta \rho\right)\left(4-\beta^{2}\right)}(\beta+2 \rho+\beta \rho+2)<0 .
\end{aligned}
$$

(3)

$$
\begin{aligned}
\prod_{d}^{N R^{*}}-\prod_{d}^{R^{*}} & =\left[(1-r) p_{d}^{N R^{*}}-c-r \phi\right] D_{d}^{N R^{*}}-\left[(1-r) p_{d}^{R^{*}}-c-r \phi\right] D_{d}^{R^{*}}<0, \\
\Pi_{r}^{N R^{*}}-\Pi_{r}^{R^{*}}= & -\frac{(\beta \rho+2)^{2}\left[\left(2-2 \alpha-2 c+\beta^{2} c+\alpha \beta\right)(1-r)+\beta(c+r \phi)\right]^{2}}{8\left(2-\beta^{2}\right)(1-r)^{2}\left(4-\beta^{2} \rho^{2}-4 \beta^{2}-4 \beta \rho\right)}<0, \\
\Pi_{s}^{N R^{*}}-\Pi_{s}^{R^{*}}= & \Pi_{r}^{N R^{*}}+\Pi_{d}^{N R^{*}}-\Pi_{r}^{R^{*}}-\Pi_{d}^{R^{*}}<0, \\
\prod_{d}^{N D^{*}}-\prod_{d}^{D^{*}}= & {\left[(1-r) p_{d}^{N D^{*}}-c-r \phi\right] D_{d}^{N D^{*}}-\left[(1-r) p_{d}^{D^{*}}-c-r \phi\right] D_{d}^{D^{*}}<0, } \\
\frac{\Pi_{r}^{N D^{*}}}{\Pi_{r}^{D^{*}}}= & \frac{1}{2}\left(\frac{1-\beta^{2}-\beta \rho}{2-\beta^{2}}\right)^{2} \times \\
& {\left[\frac{\left(4 \alpha+4 c-4-2 \beta \alpha+\beta^{2}(1-\alpha-3 c)\right)(1-r)-\beta\left(2-\beta^{2}\right)(c+r \phi)}{\left((1 / 2)(4 \alpha+4 c-4-2 \beta \alpha)+\beta \rho-\beta \alpha \rho+\beta^{2} c-\beta \rho c+\beta^{2}(1-\alpha-3 c)\right)(1-r)-\beta\left(1-\beta^{2}-\beta \rho\right)(c+r \phi)}\right]^{2}, }
\end{aligned}
$$

since $4 \alpha+4 c-4-2 \beta \alpha+\beta^{2}(1-\alpha-3 c)<(1 / 2)(4 \alpha+$ $4 c-4-2 \beta \alpha)+\beta \rho-\beta \alpha \rho+\beta^{2} c-\beta \rho c$ and $0<1-\beta^{2}-$ $\beta \rho<2-\beta^{2}$; thus, $0<\left(\Pi_{r}^{N D^{*}} / \Pi_{r}^{D^{*}}\right)<1$; that is, $\Pi_{r}^{N D^{*}}<\Pi_{r}^{D^{*}}$, 


$$
\begin{aligned}
\Pi^{N D^{*}}-\Pi^{D^{*}} & =\Pi_{r}^{N D^{*}}+\Pi_{d}^{N D^{*}}-\Pi_{r}^{D^{*}}-\Pi_{d}^{D^{*}}<0, \\
\prod_{d}^{N N^{*}}-\prod_{d}^{N^{*}} & =\left[(1-r) p_{d}^{N N^{*}}-c-r \phi\right] D_{d}^{N N^{*}}-\left[(1-r) p_{d}^{N^{*}}-c-r \phi\right] D_{d}^{N^{*}}<0, \\
\Pi_{r}^{N N^{*}}-\Pi_{r}^{N^{*}} & =-\frac{\left[\left(2-2 \alpha-2 c+\beta \alpha+\beta^{2} c\right)(1-r)+\beta(c+r \phi)\right]^{2}}{2(1-r)^{2}\left(2-\beta^{2}-\beta \rho\right)^{2}(2-\beta)^{2}(2+\beta)^{2}}\left(8+8 \beta \rho-\beta^{4}-4 \beta^{3} \rho-2 \beta^{2} \rho^{2}\right)<0, \\
\Pi_{s}^{N N^{*}}-\Pi_{s}^{N^{*}} & =\Pi_{r}^{N N^{*}}+\Pi_{d}^{N N^{*}}-\Pi_{r}^{N^{*}}-\Pi_{d}^{N^{*}}<0 .
\end{aligned}
$$

\section{G. Proof of Proposition 9}

Since $0<\rho<\left(\left(2 \sqrt{2-\beta^{2}}-2\right) / \beta\right)$ and $0<c<((2-2 \alpha+$ $\left.\alpha \beta) /\left(2-2 \beta^{2}\right)\right)$, we have $4-\beta^{2} \rho^{2}-4 \beta^{2}-4 \beta \rho>0$. Because $0<\beta<1,0<r<1$, and $0<\phi<1$, it can be easily verified that

(1)

$$
\begin{aligned}
& \frac{\partial p_{d}^{N R^{*}}}{\partial r}=\frac{(c+\phi)\left(4-\beta^{2}\right)}{4\left(2-\beta^{2}\right)(1-r)^{2}}>0, \\
& \frac{\partial p_{r}^{N R^{*}}}{\partial r}=\frac{\beta(c+\phi)}{2\left(2-\beta^{2}\right)(1-r)^{2}}>0, \\
& \frac{\partial p_{d}^{R^{*}}}{\partial r}=\frac{(c+\phi)\left(2-\beta^{2}-\beta \rho\right)}{(1-r)^{2}\left(4-\beta^{2} \rho^{2}-4 \beta^{2}-4 \beta \rho\right)}>0, \\
& \frac{\partial p_{r}^{R^{*}}}{\partial r}=\frac{2 \beta(c+\phi)}{\left(4-\beta^{2} \rho^{2}-4 \beta^{2}-4 \beta \rho\right)(1-r)^{2}}>0, \\
& \frac{\partial p_{d}^{N D^{*}}}{\partial r}=\frac{c+\phi}{2(1-r)^{2}}>0 \\
& \frac{\partial p_{r}^{N D^{*}}}{\partial r}=\frac{\beta(c+\phi)}{4(1-r)^{2}}>0 \\
& \frac{\partial p_{d}^{D^{*}}}{\partial r}=\frac{c+\phi}{2(1-r)^{2}}>0 \\
& \frac{\partial p_{r}^{D^{*}}}{\partial r}=\frac{\beta(c+\phi)}{2(1-r)^{2}}>0 \\
& \frac{\partial p_{d}^{N N^{*}}}{\partial r}=\frac{2(c+\phi)}{(1-r)^{2}\left(4-\beta^{2}\right)}>0 \text {, } \\
& \frac{\partial p_{r}^{N N^{*}}}{\partial r}=\frac{\beta(c+\phi)}{(1-r)^{2}\left(4-\beta^{2}\right)}>0, \\
& \frac{\partial p_{d}^{N^{*}}}{\partial r}=\frac{c+\phi}{(1-r)^{2}\left(2-\beta^{2}-\beta \rho\right)}>0, \\
& \frac{\partial p_{r}^{N^{*}}}{\partial r}=\frac{\beta(c+\phi)}{(1-r)^{2}\left(2-\beta^{2}-\beta \rho\right)}>0 .
\end{aligned}
$$

(2)

$$
\begin{aligned}
\frac{\partial e^{R^{*}}}{\partial r} & =\frac{\beta(c+\phi)(\beta \rho+2)}{(1-r)^{2}\left(4-\beta^{2} \rho^{2}-4 \beta^{2}-4 \beta \rho\right)}>0, \\
\frac{\partial e^{D^{*}}}{\partial r} & =\frac{\beta(c+\phi)}{2(1-r)^{2}}>0, \\
\frac{\partial e^{N^{*}}}{\partial r} & =\frac{\beta(c+r \phi)}{(1-r)^{2}\left(2-\beta^{2}-\beta \rho\right)}>0 .
\end{aligned}
$$

\section{Data Availability}

The data used to support the findings of this study are included within the article.

\section{Conflicts of Interest}

The authors declare that they have no conflicts of interest.

\section{Acknowledgments}

This research was supported by the National Natural Science Foundation of China (Grant no. 71771055), Key Projects of Natural Science of Anhui (Grant no. KJ2019A0519), Project of Natural Science of Provincial Platform (Grant no. 2020WLGH01), and City School Cooperation Project (Grant no. SXHZ202009).

\section{References}

[1] P. He, Y. He, and H. Xu, "Buy-online-and-deliver-from-store strategy for a dual-channel supply chain considering retailer's location advantage," Transportation Research Part E: Logistics and Transportation Review, vol. 144, Article ID 102127, 2020.

[2] P. Zhang, Y. He, and X. Zhao, "“Preorder-online, pickup-instore" strategy for a dual-channel retailer," Transportation Research Part E: Logistics and Transportation Review, vol. 122, pp. 27-47, 2019.

[3] D. R. Bell, S. Gallino, and A. Moreno, "Offline showrooms in omnichannel retail: demand and operational benefits," Management Science, vol. 64, no. 4, pp. 1629-1651, 2018.

[4] G. Li, L. Li, and J. Sun, "Pricing and service effort strategy in a dual-channel supply chain with showrooming effect," Transportation Research Part E: Logistics and Transportation Review, vol. 126, no. 3, pp. 32-48, 2019. 
[5] M. Li, X. Zhang, and B. Dan, "Competition and cooperation in a supply chain with an offline showroom under asymmetric information," International Journal of Production Research, vol. 58, no. 19, pp. 5964-5979, 2020.

[6] G. Li, T. Zhang, and G.-K. Tayi, "Inroad into omni-channel retailing: physical showroom deployment of an online retailer," European Journal of Operational Research, vol. 283, no. 2, pp. 676-691, 2019.

[7] G. Li, L. Li, S. P. Sethi, and X. Guan, "Return strategy and pricing in a dual-channel supply chain," International Journal of Production Economics, vol. 215, pp. 153-164, 2019.

[8] Y.-R. Li, B. Li, W. Zheng, and X. Chen, "Reveal or hide? Impact of demonstration on pricing decisions considering showrooming behavior," Omega, vol. 25, Article ID 102329, 2020.

[9] L. Nageswaran, S.-H. Cho, and A. Scheller-Wolf, "Consumer return policies in omnichannel operations," Management Science, vol. 66, no. 12, pp. 5558-5575, 2020.

[10] S. Banjo, Rampant Returns Plague E-Retailers, Wall Street Journal, New York, NY, USA, 2013, https://www.wsj.com/ articles/rampant-returns-plague-eretailers-1387752786.

[11] X. Wan, D. Li, J. Chen, and Y.-Q. Lei, "Managing customer returns strategy with the option of selling returned products," International Journal of Production Economics, vol. 230, Article ID 107794, 2020.

[12] H. Yang, J. Chen, X. Chen, and B. Chen, "The impact of customer returns in a supply chain with a common retailer," European Journal of Operational Research, vol. 256, no. 1, pp. 139-150, 2017.

[13] L.-L. Ren, Y. He, and H.-F. Song, "Price and service competition of dual-channel supply chain with consumer returns," Discrete Dynamics in Nature and Society, vol. 2014, p. 10, Article ID 565603, 2014.

[14] M.-J. Lazar, "Ecommerce Returns Statistics for 2018," https:// www.readycloud.com/info/ecommerce-returns-statistics-for2018, (Accessed 20 January 2020), 2018.

[15] J. A. Petersen and V. Kumar, "Perceived risk, product returns, and optimal resource allocation: evidence from a field experiment," Journal of Marketing Research, vol. 52, no. 2, pp. 268-285, 2015.

[16] M. Hudson, “The High Cost of Retail Returns," (June 25). https://www.thebalancesmb.com/the-high-cost-of-retailreturns-2890350, (Accessed 22 September 2019), 2019.

[17] T. Li, R. Zhang, and B. Liu, "Pricing decisions of competing supply chains under power imbalance structures," Computers \& Industrial Engineering, vol. 125, pp. 695-707, 2018.

[18] X.-X. Zheng, Z. Liu, K. W. Li, J. Huang, and J. Chen, "Cooperative game approaches to coordinating a three-echelon closed-loop supply chain with fairness concerns," International Journal of Production Economics, vol. 212, pp. 92-110, 2019.

[19] T. Li, R. Zhang, and B. Liu, "Advertising and power structures in competing supply chains," Computers \& Industrial Engineering, vol. 150, Article ID 106917, 2020.

[20] S. Gallino and A. Moreno, "The value of fit information in online retail: evidence from a randomized field experiment," Manufacturing \& Service Operations Management, vol. 20, no. 4, pp. 768-787, 2018.

[21] C. Li, Q. Liu, P. Zhou, and H. Huang, "Optimal innovation investment: the role of subsidy schemes and supply chain channel power structure," Computers \& Industrial Engineering, vol. 157, Article ID 107291, 2021.

[22] T. Li, J. Xie, and X. Liu, "Consumer return policies in presence of a P2P market,” Omega, vol. 97, Article ID 102092, 2020.
[23] S. Zhang, C. Wang, C. Yu, and Y. Ren, "Governmental cap regulation and manufacturer's low carbon strategy in a supply chain with different power structures," Computers \& Industrial Engineering, vol. 134, pp. 27-36, 2019.

[24] B.-R. Zheng, N. Yu, L. Jin, and H.-S. Xia, "Effects of power structure on manufacturer encroachment in a closed-loop supply chain," Computers \& Industrial Engineering, vol. 137, Article ID 106062, 2020.

[25] Y. Ranjbar, H. Sahebi, J. Ashayeri, and A. Teymouri, "A competitive dual recycling channel in a three-level closed loop supply chain under different power structures: pricing and collecting decisions," Journal of Cleaner Production, vol. 272, Article ID 122623, 2020.

[26] X.-M. Zhang, Y.-Y. Li, Z. Liu, and Q.-W. Li, “Coordination contracts of dual-channel supply chain considering advertising cooperation," International Journal of Information Systems and Supply Chain Management, vol. 14, no. 1, pp. 55-89, 2021.

[27] B. Jing, "Showrooming and webrooming: information externalities between online and offline sellers," Marketing Science, vol. 37, no. 3, pp. 333-506, 2018.

[28] Y. Sun, Z. Wang, and X. Han, "Supply chain channel strategies for online retailers: whether to introduce web showrooms?" Transportation Research Part E: Logistics and Transportation Review, vol. 144, Article ID 102122, 2020.

[29] S. S. Sana, "Price competition between green and non green products under corporate social responsible firm," Journal of Retailing and Consumer Services, vol. 55, Article ID 102118, 2020.

[30] N. Viejo-Fernández, M. J. Sanzo-Pérez, and R. VázquezCasielles, "Is showrooming really so terrible? Start understanding showroomers," Journal of Retailing and Consumer Services, vol. 54, Article ID 102048, 2020.

[31] Z. Liu, L. Lu, and X. Qi, "The showrooming effect on integrated dual channels," Journal of the Operational Research Society, vol. 71, no. 9, pp. 1347-1356, 2020.

[32] A. Mehra, S. Kumar, and J.-S. Raju, ““Competitive strategies for brick-and-mortar store to counter "showrooming"” Management Science, vol. 64, no. 7, pp. 3076-3090, 2017.

[33] A. Rapp, T. L. Baker, D. G. Bachrach, J. Ogilvie, and L. S. Beitelspacher, "Perceived customer showrooming behavior and the effect on retail salesperson self-efficacy and performance," Journal of Retailing, vol. 91, no. 2, pp. 358-369, 2015.

[34] P. Basu, S. Basak, B. Avittathur, and S. Sikdar, “'A game theoretic analysis of multichannel retail in the context of "showrooming"” Decision Support Systems, vol. 103, pp. 3445, 2017.

[35] P. J. Schneider and S. Zielke, "Price versus service: can retailers beat showrooming with competence?" Journal of Retailing and Consumer Services, vol. 61, Article ID 102592, 2021.

[36] M. A. Shakir Goraya, J. Zhu, M. S. Akram, M. A. Shareef, A. Malik, and Z. A. Bhatti, "The impact of channel integration on consumers' channel preferences: do showrooming and webrooming behaviors matter?" Journal of Retailing and Consumer Services, vol. 23, Article ID 102130, 2020.

[37] M. S. Altug and T. Aydinliyim, "Counteracting strategic purchase deferrals: the impact of online retailers' return policy decisions," Manufacturing \& Service Operations Management, vol. 18, no. 3, pp. 376-392, 2016.

[38] J. Chen and B. Chen, "Competing with customer returns policies," International Journal of Production Research, vol. 54, no. 7, pp. 2093-2107, 2016. 
[39] C. Wang, J. Chen, L. Wang, and J. Luo, "Supply chain coordination with put option contracts and customer returns," Journal of the Operational Research Society, vol. 71, no. 6, pp. 1003-1019, 2020.

[40] J. Chen, B. Chen, and W. Li, "Who should be pricing leader in the presence of customer returns?" European Journal of Operational Research, vol. 265, no. 2, pp. 735-747, 2018.

[41] M. Radhi and G. Zhang, "Pricing policies for a dual-channel retailer with cross-channel returns," Computers \& Industrial Engineering, vol. 119, pp. 63-75, 2018.

[42] M. S. Akturk, M. Ketzenberg, and B. Yildı, "Managing consumer returns with technology-enabled countermeasures," Omega, vol. 102, Article ID 102337, 2021.

[43] M. Ren, J. Liu, S. Feng, and A. Yang, "Pricing and return strategy of online retailers based on return insurance," Journal of Retailing and Consumer Services, vol. 59, Article ID 102350, 2021.

[44] T. Javadi, N. Alizadeh-Basban, S. Asian, and A. Hafezalkotob, "Pricing policies in a dual-channel supply chain considering flexible return and energy-saving regulations," Computers \& Industrial Engineering, vol. 135, pp. 655-674, 2019.

[45] I. E. Nielsen, S. Majumder, S. S. Sana, and S. Saha, "Comparative analysis of government incentives and game structures on single and two-period green supply chain," Journal of Cleaner Production, vol. 235, pp. 1371-1398, 2019.

[46] R.-H. Tang and L. Yang, "Impacts of financing mechanism and power structure on supply chains under cap-and-trade regulation," Transportation Research Part E: Logistics and Transportation Review, vol. 139, Article ID 101957, 2020.

[47] S. S. Sana, "A structural mathematical model on two echelon supply chain system," Annals of Operations Research, vol. 299, 2021.

[48] Z. Luo, X. Chen, and M. Kai, "The effect of customer value and power structure on retail supply chain product choice and pricing decisions,” Omega, vol. 77, pp. 115-126, 2018.

[49] M.-A.-N. Agi and X.-H. Yan, "Greening products in a supply chain under market segmentation and different channel power structures," International Journal of Production Economics, vol. 223, Article ID 107523, 2020.

[50] L. Yang, J. Ji, M. Wang, and Z. Wang, "The manufacturer's joint decisions of channel selections and carbon emission reductions under the cap-and-trade regulation," Journal of Cleaner Production, vol. 193, pp. 506-523, 2018.

[51] B. Dan, G. Xu, and C. Liu, "Pricing policies in a dual-channel supply chain with retail services," International Journal of Production Economics, vol. 139, no. 1, pp. 312-320, 2012.

[52] X.-M. Zhang, Q.-W. Li, Z. Liu, and C.-T. Chang, "Optimal pricing and remanufacturing mode in a closed-loop supply chain of WEEE under government fund policy," Computers \& Industrial Engineering, vol. 151, Article ID 106951, 2021.

[53] X.-M. Zhang, C.-H. Ma, H.-R. Chen, and G.-H. Qi, ““Impact of retailer's vertical and horizontal fairness concerns on manufacturer's online channel mode," Discrete Dynamic in Nature and Society, vol. 2021, Article ID 6692582, 12 pages, 2021.

[54] Y. Yan, R. Zhao, and Z. Liu, "Strategic introduction of the marketplace channel under spillovers from online to offline sales," European Journal of Operational Research, vol. 267, no. 1, pp. 65-77, 2018.

[55] Y. Akçay, T. Boyacı, and D. Zhang, "Selling with money-back guarantees: the impact on prices, quantities, and retail profitability," Production and Operations Management, vol. 22, no. 4, pp. 777-791, 2013.
[56] R.-M. Difrancesco and A. Huchzermeier, "Multichannel retail competition with product returns: effects of restocking fee legislation," Electronic Commerce Research and Applications, vol. 43, pp. 1-45, 2020.

[57] D.-L. Jin, O. Caliskan-Demirag, F. Chen, and M. Huang, “"Omnichannel retailers' return policy strategies in the presence of competition," International Journal of Production Economics, vol. 225, pp. 1-35, 2019.

[58] Z. Liu, W.-K. Li, J. Tang, B.-G. Gong, and J. Huang, "Optimal operations of a closed-loop supply chain under a dual regulation," International Journal of Production Economics, vol. 233, Article ID 107997, 2021.

[59] S. Panda, N. M. Modak, and L. E. Cárdenas-Barrón, "Coordinating a socially responsible closed-loop supply chain with product recycling," International Journal of Production Economics, vol. 188, pp. 11-21, 2017.

[60] Z. Liu, X.-X. Zheng, D.-F. Li, C.-N. Liao, and J.-B. Sheu, “A novel cooperative game-based method to coordinate a sustainable supply chain under psychological uncertainty in fairness concerns," Transportation Research Part E: Logistics and Transportation Review, vol. 147, Article ID 102237, 2021.

[61] Y.-Y. Wang, M. Su, L. Shen, and R.-Y. Tang, "Decisionmaking of closed-loop supply chain under corporate social responsibility and fairness concerns," Journal of Cleaner Production, vol. 284, Article ID 125373, 2021.

[62] W. Shi, H.-R. Chen, X.-M. Zhang, and C.-H. Ma, "Optimal alliance strategy and its impact in a closed-loop supply chain by considering greenness and service effort," Mathematical Problems in Engineering, vol. 2021, Article ID 6676482, 17 pages, 2021. 